\title{
Aerosol airmass type mapping over the Urban Mexico City region from space-based multi-angle imaging
}

\author{
F. Patadia ${ }^{1,2}$, R. A. Kahn², J. A. Limbacher ${ }^{2,3}$, S. P. Burton ${ }^{4}$, R. A. Ferrare ${ }^{4}$, C. A. Hostetler ${ }^{4}$, and J. W. Hair ${ }^{4}$ \\ ${ }^{1}$ GESTAR, Morgan State University, Baltimore, MD 21251, USA \\ ${ }^{2}$ Climate \& Radiation Laboratory, NASA Goddard Space Flight Center, Greenbelt, MD 20771, USA \\ ${ }^{3}$ Science Systems and Applications, Inc., Lanham, MD 20706, USA \\ ${ }^{4}$ NASA Langley Research Center, Hampton VA, 23681, USA
}

Correspondence to: F. Patadia (falguni.patadia@nasa.gov)

Received: 6 January 2013 - Published in Atmos. Chem. Phys. Discuss.: 22 March 2013

Revised: 30 July 2013 - Accepted: 31 July 2013 - Published: 27 September 2013

Abstract. Using Multi-angle Imaging SpectroRadiometer (MISR) and sub-orbital measurements from the 2006 INTEX-B/MILAGRO field campaign, in this study we explore MISR's ability to map different aerosol air mass types over the Mexico City metropolitan area. The aerosol air mass distinctions are based on shape, size and single scattering albedo retrievals from the MISR Research Aerosol Retrieval algorithm. In this region, the research algorithm identifies dust-dominated aerosol mixtures based on non-spherical particle shape, whereas spherical biomass burning and urban pollution particles are distinguished by particle size. Two distinct aerosol air mass types based on retrieved particle microphysical properties, and four spatially distributed aerosol air masses, are identified in the MISR data on 6 March 2006. The aerosol air mass type identification results are supported by coincident, airborne high-spectral-resolution lidar (HSRL) measurements. Aerosol optical depth (AOD) gradients are also consistent between the MISR and sub-orbital measurements, but particles having single-scattering albedo of $\approx 0.7$ at $558 \mathrm{~nm}$ must be included in the retrieval algorithm to produce good absolute AOD comparisons over pollutiondominated aerosol air masses. The MISR standard V22 AOD product, at $17.6 \mathrm{~km}$ resolution, captures the observed AOD gradients qualitatively, but retrievals at this coarse spatial scale and with limited spherical absorbing particle options underestimate AOD and do not retrieve particle properties adequately over this complex urban region. However, we demonstrate how AOD and aerosol type mapping can be accomplished with MISR data over complex urban regions, provided the retrieval is performed at sufficiently high spatial resolution, and with a rich enough set of aerosol components and mixtures.

\section{Introduction}

Aerosols play an important role in global climate forcing through their direct and indirect effects. They also have significant regional impacts on both climate and air quality (IPCC, 2007). Information on aerosol type is crucial for improving our understanding and assessment of anthropogenic influences of aerosols on climate. Particulate matter (PM), especially particles with aerodynamic diameter $<2.5 \mu \mathrm{m}$, have known health impacts, such as cardiopulmonary diseases (Schwartz and Marcus, 1990; Saldiva et al., 1995; Krewski et al., 2000). More generally, aerosol size information is of value for particulate matter air quality assessment. The spatial and temporal distribution of aerosol microphysical and optical properties is heterogeneous in nature and is caused by the wide variety of aerosol sources around the globe and relatively short atmospheric lifetime. In urban regions such as Mexico City, aerosols originate most commonly from industrial and domestic emissions, biomass burning, local transportation, and local wind-driven dust (Moffet et al., 2008; Stone et al., 2008; Aiken et al., 2010). Aerosol sources and aerosol types can vary on short spatial scales $(\sim$ few $\mathrm{km})$ in this region. Air quality standards are frequently violated by high PM concentrations in the Mexico City area (Molina and Molina, 2004), and the aerosols also have the potential to affect the air quality and 
climate of surrounding areas. For example, during the dry season, regional winds can transport aerosols from Mexico to the southeast United States (Wang et al., 2006; Voss et al., 2010). The study of aerosols therefore warrants continuous synoptic-scale monitoring, which can best be achieved through satellite measurements.

Although satellites provide global monitoring of aerosol optical depth (AOD), few space-borne sensors have the capability to distinguish different aerosol types. The Multiangle Imaging SpectroRadiometer (MISR) aboard the Terra satellite is one instrument that can retrieve some information about aerosol shape, size and single scattering albedo (SSA) under good retrieval conditions (Kahn et al., 2005, 2010). Particle type represents a constraint on particle origin and composition, and can contribute to mapping aerosol evolution and transport. Under good retrieval conditions and depending on the aerosol type, the Version 22 MISR Standard Aerosol Retrieval algorithm can distinguish two or three aerosol size groupings, about two SSA categories (absorbing vs. non-absorbing) and spherical vs. non-spherical particles. Over urban areas, Kahn et al. (2010) showed with MISR data that the aerosols are localized and vary over small spatial scales. This suggests the necessity for high-resolution AOD retrievals over urban areas.

Comparisons of satellite aerosol property retrievals against suborbital measurements, such as those collected during field campaigns, provide unique opportunities to refine and assess the quality of the satellite retrievals. Using a combination of MISR standard aerosol retrievals (Martonchik et al., 1998, 2009) and MISR research algorithm retrievals (Kahn et al., 2001; Kahn and Limbacher 2012), along with ground and aircraft data from the Intercontinental Chemistry Transport Experiment-B (INTEX-B) field campaign, we analyze MISR aerosol retrievals in detail over the Mexico City area in this study. Although the MISR operational algorithm attempts to retrieve aerosol properties globally, and computational constraints limit the range of aerosol models that can be considered, the research algorithm allows us to explore the information content of the MISR data for a much broader range of particle types, and at significantly higher spatial resolution for this application.

Our validation data comes from the host of instruments that obtained aerosol physical and optical property measurements during the INTEX-B field campaign. Our study adds information about the performance of MISR's Standard aerosol retrieval algorithm to the existing literature, and also uses the satellite data to map AOD and aerosol type over the Mexico City Metropolitan area (MCMA) in more detail with the MISR research algorithm, providing regional context for the aerosol measurements made by multiple, suborbital sensors. We focus on identifying different aerosol types in the complex Mexico City urban setting, and on mapping AOD gradients and aerosol air mass types to the extent possible, using MISR data in the MCMA study region. Previous studies relating to MISR aerosol-type sensitivity fo- cused on biomass burning and dust-dominated regions (Chen et al., 2008; Kalashnikova and Kahn, 2006; Kahn et al., 2009a), and locations affected by thin cirrus (Pierce et al., 2010), whereas this study focuses on the aerosols over the urban Mexico City basin. The paper is organized as follows: Sect. 2 briefly describes the datasets used, Sect. 3 discusses the sub-orbital constraints on aerosol properties for our study days, results from MISR research algorithm are discussed in Sect. 4, Sect. 5 presents notes on the sensitivity of MISR retrievals over our study area and a summary of this study is given in Sect. 6.

\section{Study area and data used}

The Mexico City Metropolitan area, consisting of the heavily populated Mexico City basin, is our study region (see Fig. 1). Mexico City is one of the world's largest megacities, and has undergone rapid urban development. We analyze data for two golden days, 6 and 15 March 2006, defined as days during which (1) MISR observations were made over the study region, (2) coincident ground and air observations are available, and (3) the key observational requirements of relatively cloud-free conditions and the presence of aerosols from different sources are met. The ground-based and aircraft data used in this study are described briefly in this section, along with the Version 22 MISR Level 2 standard aerosol product.

\subsection{Ground-based and aircraft measurements}

During the field campaign, Aerosol Robotic Network (AERONET) CIMEL sun photometers were deployed at sites labeled as T0, T1 in Fig. 1, and a third at Tampico, about $500 \mathrm{~km}$ northeast of Mexico City (not shown), and five Microtops II sun photometers were deployed, one at each of the Hidalgo, UNAM, Corena, TEC, and UAMI sites (de Almeida Castanho et al., 2007; Molina et al., 2008), also shown in Fig. 1. The AERONET is a global, ground-based network of well-calibrated sun photometers that measure spectral AOD at $340,380,440,500,670,870,1020$ and $1640 \mathrm{~nm}$ with an accuracy of about \pm 0.015 (Holben et al., 1998, 2001; Eck et al., 1999). AERONET also retrieves other column-effective aerosol properties, such as size distribution, refractive index, single-scattering albedo (SSA), asymmetry parameter $(g)$ and phase function, with varying frequency and degrees of accuracy (Dubovik and King, 2000). We use version-2 level-2 AOD and Angstrom Exponent (AE) data from the T0, $\mathrm{T} 1$ and Tampico stations for the two golden study days. The Microtops II are handheld sun photometers that measure solar radiance at five spectral wavelengths and provide AOD to within \pm 0.03 (Ichoku et al., 2002). We use the AOD at visible wavelengths from all five ground-based Microtops sites to evaluate the corresponding values from both the MISR L2 aerosol product and the MISR research algorithm. For each ground-based site, Table S1 summarizes all the available 

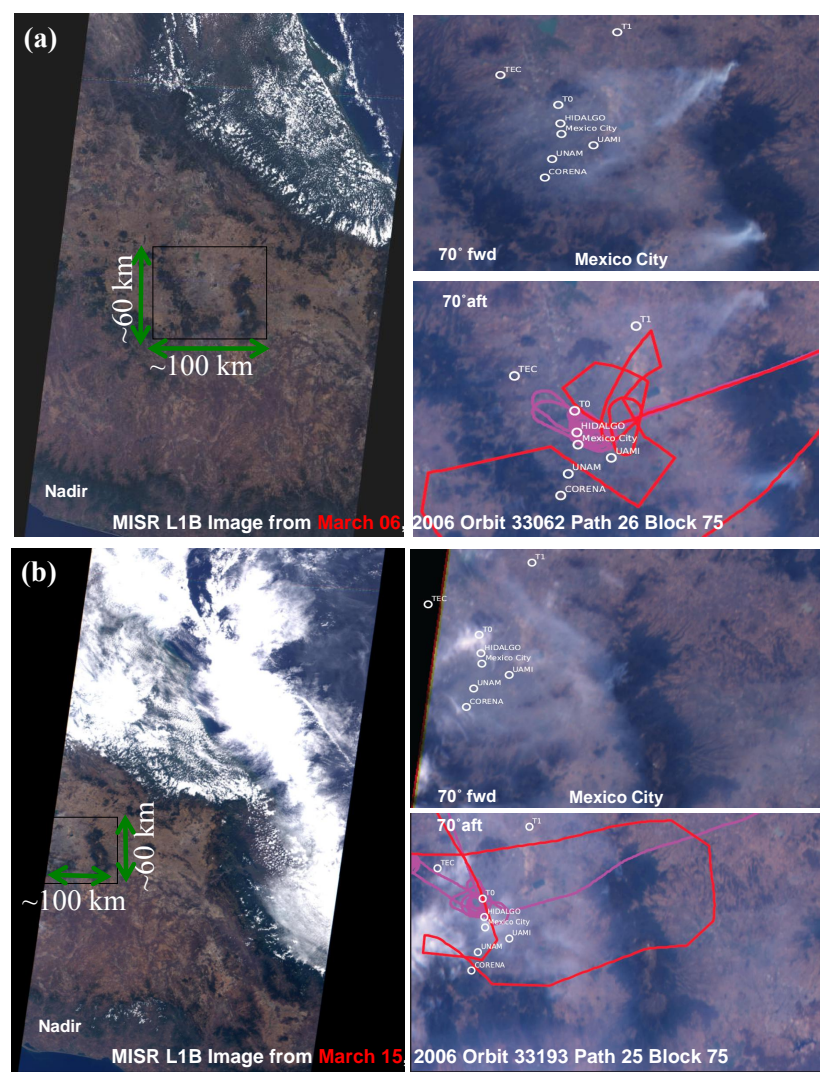

Fig. 1. (a) Nadir, $70^{\circ}$ forward and $70^{\circ}$ aft ward view of Mexico City from MISR (L1B RGB image) on 6 March 2006. Overlaid are locations of ground-based instruments and the J31 (pink) and B200 (red) flight tracks (bottom right image). Names of the ground based stations are indicated in the Figure. These also include the AERONET stations at supersites $\mathrm{T} 0$ and $\mathrm{T} 1$. The $70^{\circ}$ forward view image shows fires burning at atleast 2 different locations on the mountains to the east of Mexico City and the transport of smoke from these fires over the MCMA study area. (b) Same as (a), except, it is for 15 March 2006. More burning activity can be seen on this day (see top right image) compared to (a) for 6 March 2006. Also, notice the presence of clouds around T0 supersite (top right image) and around central Mexico City (bottom right image).

ground and aircraft instruments, the aerosol properties used, geographic location and the availability of different observations on 6 and 15 March 2006.

During the MILAGRO/INTEX-B field campaign, eight instrumented research aircraft from the United States made measurements. Details on the principal airborne platforms that participated in the INTEX-B campaign and the scientific payloads on each aircraft can be found in Singh et al. (2009) and Molina et al. (2010). Rogers et al. (2009) describe the High Spectral Resolution Lidar (HSRL) carried by the B200 aircraft. Only the J-31 and B200 aircraft acquired coincident aerosol property measurements on both our case study days. For these days, we use primarily the vertical profiles of aerosol extinction, backscatter and depolarization, along with aerosol classification products, from the HSRL onboard the B200 to evaluate aerosol retrievals from the MISR standard and research algorithms.

\subsection{The MISR L2 aerosol product}

The Multi-angle Imaging SpectroRadiometer (MISR) is on board Terra, one of the NASA Earth Observing System (EOS) of satellites. Terra was launched on 18 December 1999 into a sun-synchronous orbit at an altitude of $704 \mathrm{~km}$, and has an equatorial crossing time of 10:30 a.m. LT (north to south). MISR images earth in four spectral bands centered at $446,558,672,867 \mathrm{~nm}$, and has nine push-broom cameras viewing at nine different angles, $0, \pm 26.1, \pm 45.6, \pm 60.0$, and \pm 70.5 degrees, covering the nadir, forward, and aft directions along the line-of-flight. The MISR level 2 aerosol data product (MIL2ASAE) contains: (1) aerosol optical depth (AOD) in 4 spectral channels, (2) fraction of AOD for three different particle size ranges, (3) fraction AOD assigned to nonspherical particles, (4) spectral single-scattering albedo, (5) angstrom exponent, other parameters related to aerosol retrieval quality, and geographical information. In this paper, we use the MIL2ASAE Version 22 data product. The L2 aerosol optical depth is reported at $17.6 \times 17.6 \mathrm{~km}$ resolution. A detailed description of the MISR aerosol retrieval is given in Martonchik et al. (1998, 2009) and Kahn et al. (2009b).

Validation of MISR AOD $(558 \mathrm{~nm})$ against AERONET shows that about $70-75 \%$ of MISR AOD retrievals fall within 0.05 or $20 \%$ of AERONET AOD and about $50-55 \%$ are within 0.03 or $10 \%$ of AERONET AOD for globally distributed sites (Kahn et al., 2010). The AOD is designated as Stage 3 validated, whereas other aerosol properties such as SSA, AE and fractional AOD are Stage 2 validated, as described in the MISR Data Quality Statement distributed with the data products (http://eosweb.larc.nasa.gov/PRODOCS/misr/Quality_ Summaries/misr_qual_stmts_new.html). The MISR research algorithm used in this study is described in Sect. 3.3.

\section{Suborbital constraints on aerosol properties for the MISR golden days}

Figure 1a shows the MISR L1B RGB images (Nadir, $70^{\circ}$ Forward and $70^{\circ}$ Aftward cameras) from 6 March 2006 for our study region. The B200 flight track (with the HSRL instrument) for the same day is superposed as a red line on the $70^{\circ}$ forward camera image. The $\mathrm{J} 31$ flight track is shown as a pink line on this figure, as this aircraft carried the AATS 14 instrument (Redemann et al., 2009), from which a few measurements coincident with the MISR overpass were also obtained. The key ground-based sites are also marked on the same image. Figure $1 \mathrm{~b}$ is similar to Fig. 1a, except it is for 15 March 2006. In the following section, we use the data from all these ground-based and airborne instruments to assess 
aerosol characteristics, and spatial and temporal variability, on the two case study days. These results are then used to validate and test the limits of the MISR retrievals in the subsequent section. AOD from the J31 and the ground-based instruments used in this study are interpolated to MISR midvisible wavelength $(558 \mathrm{~nm})$ using the Ångström formula, and is reported at $558 \mathrm{~nm}$ throughout this paper.

\subsection{Suborbital constraints on the aerosol environment for 6 March 2006}

On 6 March 2006, AOD is available over four of the Microtops ground stations and over three AERONET stations (Tables S1b and S1c). In Fig. 2, the lines in different colors depict the AOD variations over different ground stations (mapped in Fig. 1) in the field campaign area. Aerosol optical depth (Fig. 2a) shows diurnal variation with average AOD $(558 \mathrm{~nm})$ of 0.1 in the forenoon (16:00 UTC) and $\sim 0.4$ in the afternoon hours (by 21:00 UTC) over central Mexico City. Lower AOD observations spaced about $30 \mathrm{~km}$ apart at the $\mathrm{T} 1$ and Tampico sites to the northeast of Mexico City suggest gradients in AOD in the Mexico City basin. From the MISR RGB image for 6 March (Fig. 1a), we find at least two biomass-burning fires, one each to the northeast and southeast of Mexico City. The clockwise wind circulation (Fast et al., 2007) on this day explains the transport of aerosols from the fire locations into the field campaign region, possibly missing the AERONET supersites farther north at T1 and Tampico. Basin scale wind pattern on this day falls into the O3-South category (de Foy et al., 2008) that is characterized by east-west convergence zones and southwest venting, which explains AOD pattern over the above AERONET supersites.

We can infer the type of aerosols in the study area by analyzing the vertical distribution of aerosol intensive properties from the HSRL measurements (Burton et al., 2012). Figure 3 shows the vertical distribution of aerosol properties on 6 March 2006 as measured by the HSRL instrument on B200 Flight 10. The HSRL made several observations around the Mexico City area from 16:75 to 17:75 UTC, and in the discussion below we concentrate on this time window, as MISR passed over the area at 17:25 UTC. The aerosol extinction profiles at $532 \mathrm{~nm}$ (Fig. 3a) show high extinction at the surface and at 3.5 to $5 \mathrm{~km}$ a.s.l. (see red colors). This shows the high aerosol concentrations both in the boundary layer and higher in the atmosphere. During the MILAGRO campaign, the maximum daily mixing layer depths always reached $4.2 \mathrm{~km}$ a.s.l. and frequently extended to $6.2 \mathrm{~km}$ a.s.l. (Shaw et al., 2007). Mexico City is at an elevation of $\sim 2.24 \mathrm{~km}$ a.s.l. Figure $3 \mathrm{~b}$, c and d, respectively, present the aerosol extinction to backscatter ratio $(532 \mathrm{~nm})$, aerosol wavelength dependence $(1064 \mathrm{~nm} / 532 \mathrm{~nm})$ or the backscatter related Angstrom exponent, and the aerosol depolarization ratio $(532 \mathrm{~nm})$. The aerosol extinction to backscatter ratio (Fig. 3b) has high values near the surface at some locations (e.g., see values corre-
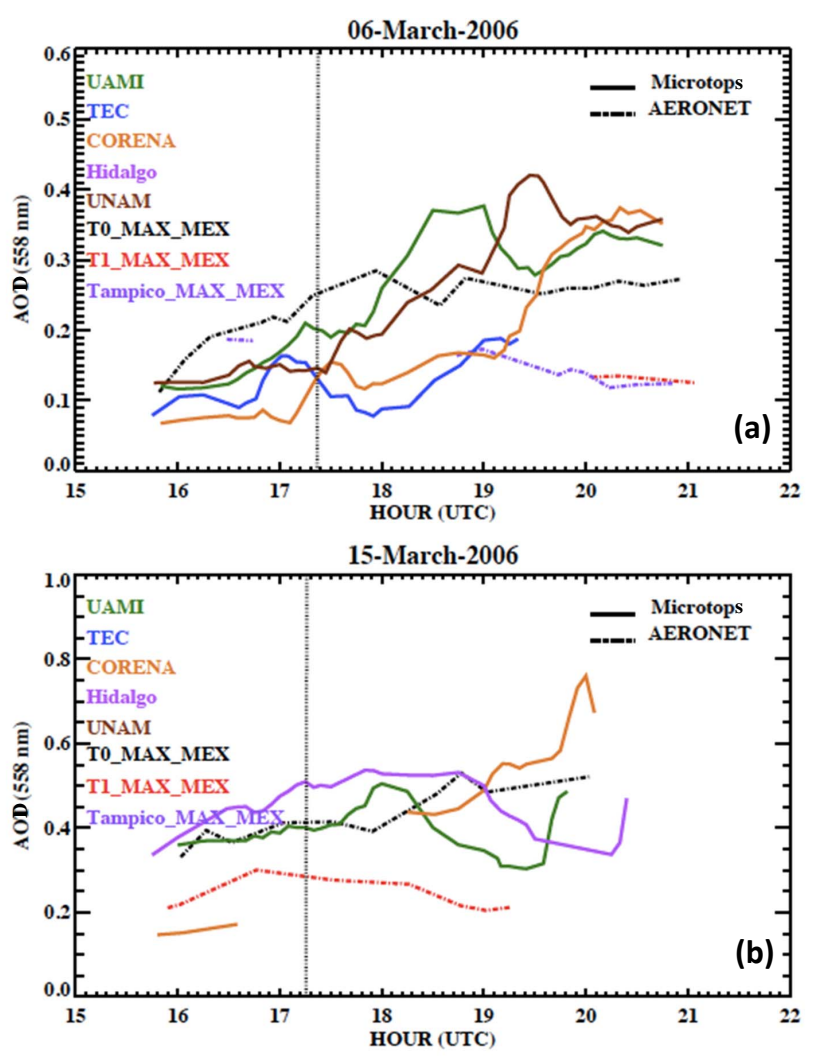

Fig. 2. (a) Diurnal variation of AOD $(558 \mathrm{~nm})$ on 6 March 2006, over the ground based stations (shown in Fig. 1) in MILAGRO/INTEX-B field campaign area around Mexico City. Aerosol optical depth from AERONET stations at supersites T0, $\mathrm{T} 1$ and Tampico are also shown. (b) Same as (a) but for 15 March 2006.

sponding to 17:20-17:25 UTC). In this time window, aerosol wavelength dependence $(1064 / 532 \mathrm{~nm})$ shows a similar pattern (Fig. 3c) whereas the aerosol depolarization ratio is low (Fig. 3d). High extinction-to-backscatter ratio, high wavelength dependence and low depolarization values can indicate the presence of urban aerosol, as shown in the HSRL classification result in Fig. 3e. On the other hand, high depolarization values (e.g., below $\sim 3 \mathrm{~km}$ and between 17:3517:40 UTC in Fig. 3d) are indicative of the presence of dust particles (see Fig. 3e) (Burton et al., 2012). Qualitative classification of aerosol intensive parameters measured by HSRL (Burton et al., 2012), shown in Fig. 3e, indicates the presence of three distinct aerosol types (dusty mix, smoke and urban pollution particles) on 6 March. It is noteworthy that the dusty mix type identified by HSRL here is not pure dust. This identification occurs when depolarization measurements indicate the presence of dust along with other components (particularly smoke or pollution) that are not distinguishable by the HSRL (see Burton et al., 2012 for details). Several other studies that analyzed the aerosol optical and chemical properties during the field campaign (e.g., Marr et al., 2006; Marley 
(a) ${ }_{5}^{\text {HSRL18200 }}$

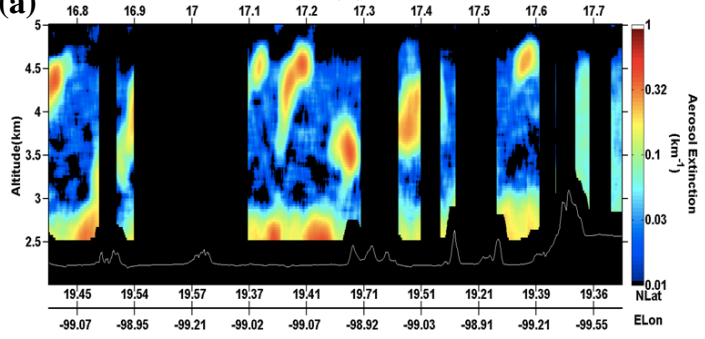

(c)

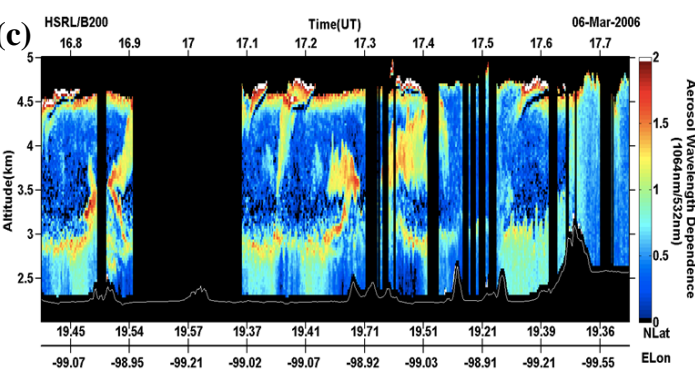

(e)

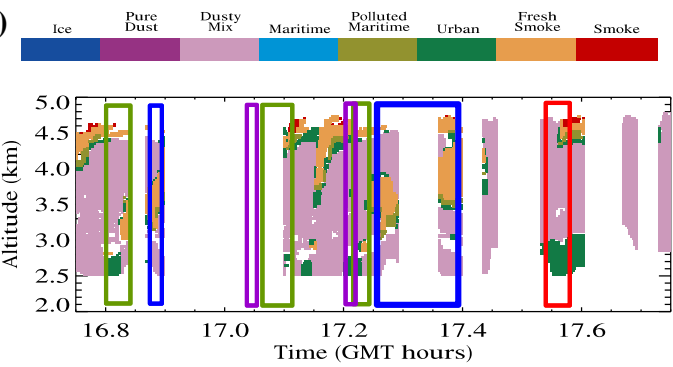

(b)

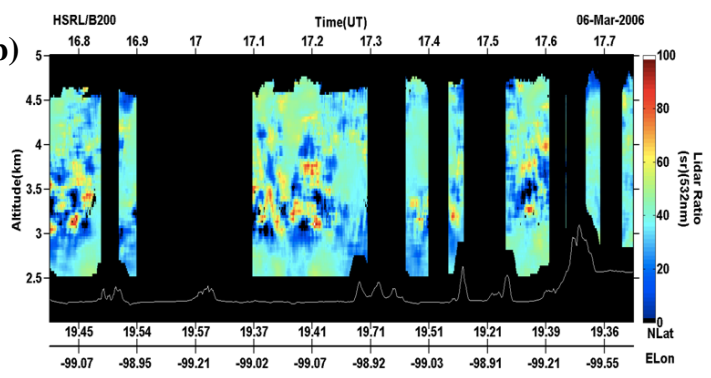

(d)
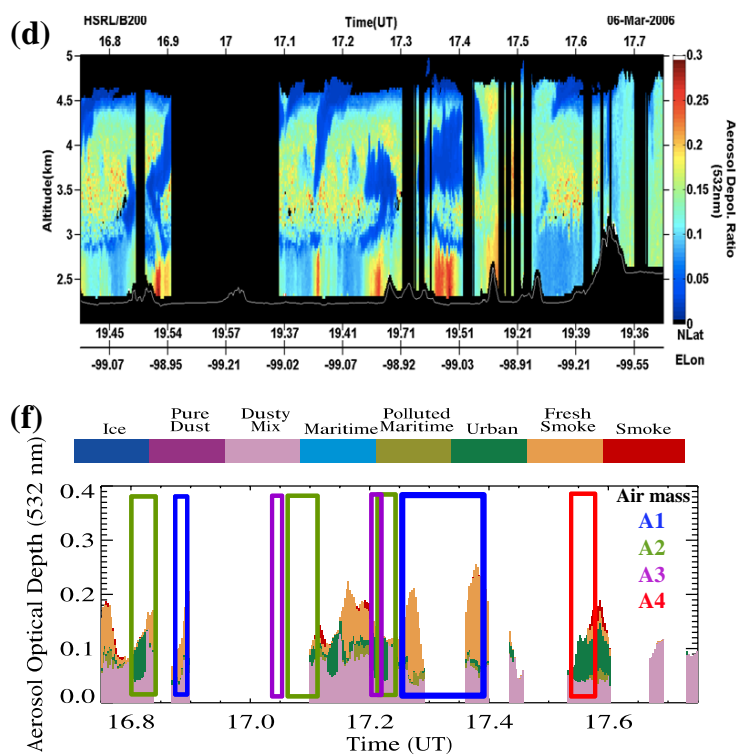

Fig. 3. HSRL observation on 6 March 2006: (a) aerosol extinction (b) aerosol extinction to back-scatter (Lidar) ratio (c) aerosol wavelength dependence (d) aerosol depolarization ratio (e) vertical distribution of aerosol types identified by HSRL (f) AOD attributed to aerosol types identified by HSRL. The approximate intersections of HSRL observations with the four aerosol air masses, as identified by MISR, are marked in (e) and (f). The legend for the air mass is shown in (f). Note that air masses over some region were observed multiple times by HSRL as the B200 aircraft circled in the study region (see Fig. 1a for B200 flight path). The elevations shown are above sea level (a.s.l.).

et al., 2007, 2009a; Stone et al., 2008; Querol et al., 2008; Corr et al., 2009; Paredes-Miranda et al., 2009; Bergstrom et al., 2010; De Foy et al., 2011) corroborate the aerosol type results from the HSRL and add detail, suggesting that the study area contained urban aerosols, including black carbon and organic matter, and mineral dust aerosols during the campaign period. Ground-based instruments also observed threeto-four aerosol size modes that are likely from these different aerosol types in the study area.

\subsection{Suborbital constraints on the aerosol environment for 15 March 2006}

In contrast to 6 March, the AOD from ground stations is higher in the study area on 15 March and there is not much variation in the AOD throughout the day (Fig. 2b). However, similar to 6 March, a spatial AOD gradient between central Mexico City and its surrounding region is observed in Fig. 2b. The lack of diurnal variation on 15 March can be attributed to locally uniform spatial mixing of aerosols due to high winds $\left(15 \mathrm{~m} \mathrm{~s}^{-1}\right)$ associated with a cold surge event in the study area (Fast et al., 2007). Cold Surge events vent in the southwest to north to southeast direction, with less southward venting (de Foy et al., 2008). Kleinman et al. (2009) analyzed the DMA and PCASP aircraft measurements of aerosol size distribution and found three-to-four modes in MCMA on 15 March. This aerosol size distribution is produced by multiple aerosol sources in the region. Moffet et al. (2008) and Stone et al. (2008) suggest that the submicron-mode aerosols are comprised of industrial emissions, biomass and biofuel burning and aged organic carbon (OC). Aiken et al. (2010) show that the dominant source of BB OC aerosols found in the Mexico City area are from forest fires burning in the surrounding mountains. The coarse mode was dominated by inorganic dust particles, $50 \%$ of which were coated with OC (Moffet et al., 2008). Wang et al. (2010) suggest traffic emissions, aging of aerosols, local photochemical production of secondary aerosol species 

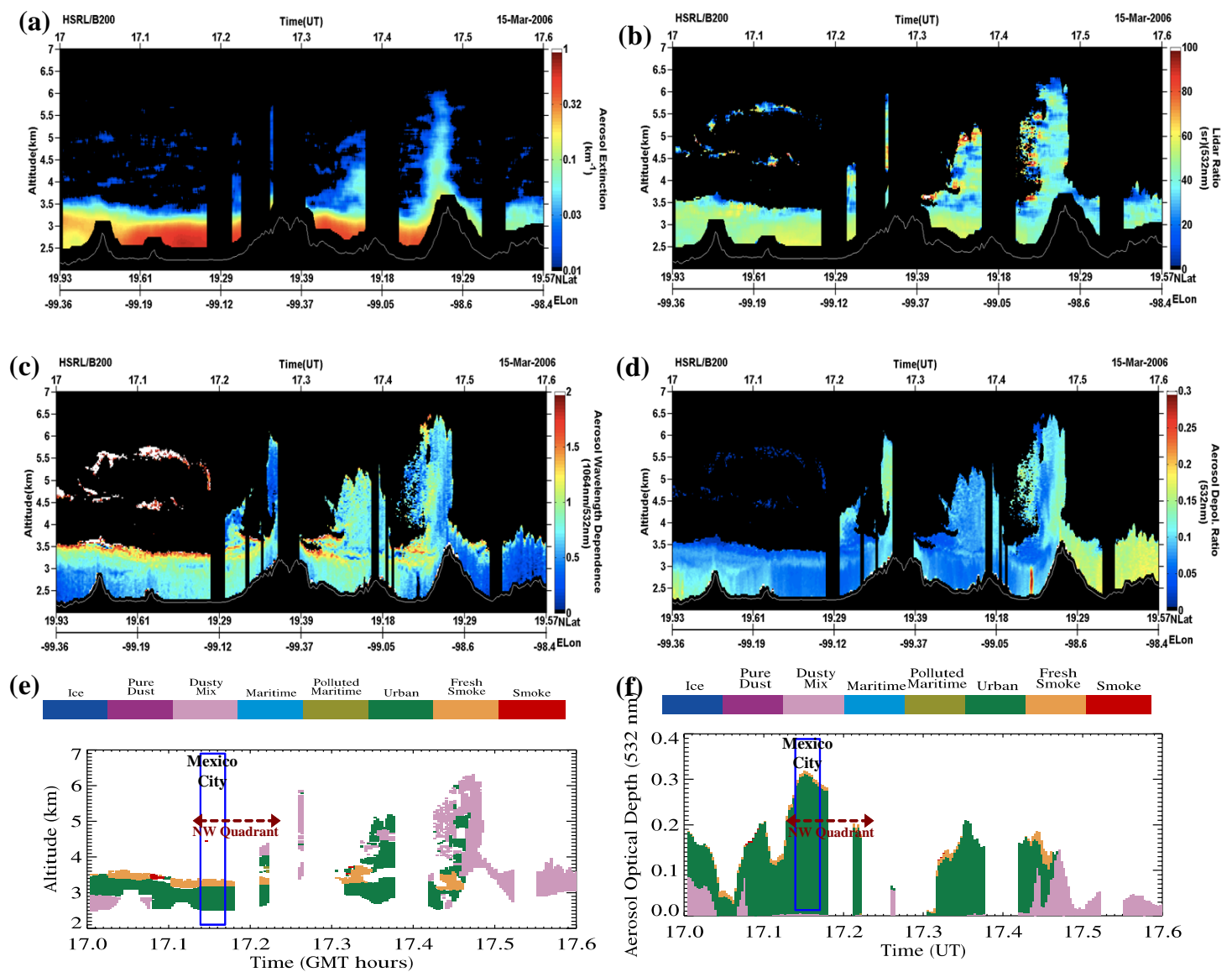

Fig. 4. HSRL observation on 15 March 2006: (a) aerosol extinction (b) aerosol extinction to back-scatter (Lidar) ratio (c) aerosol wavelength dependence (d) aerosol depolarization ratio (e) vertical distribution of aerosol types identified by HSRL (f) AOD attributed to aerosol types identified by HSRL. Blue box in (e) and (f) depicts the flight path over Mexico City.

and wind-blown dust as other sources of aerosols in MCMA. Analysis of the HSRL-measured intensive aerosol properties over our study area between 17:05 and 17:35 UTC on this day (Fig. 4) also shows that urban aerosols accounted for nearly $80 \%$ (median value) of the total AOD.

Based on the analysis of aerosol properties measured by ground-based and aircraft instruments on our case study days, the aerosol types found in the study area are again comprised of smoke, urban pollution and dust aerosols. However, the meteorology of the region is different on these days, which leads to differences in the spatial and temporal distributions of aerosols. Wang et al. (2010) suggest that during the daytime, over the Mexico City area, changes in aerosol size and composition occur over time scales of about a few hours. Spatial gradients in AOD and size distribution measured at various surface sites also suggest aerosol variability at small spatial scales. The selection of aerosol models for MISR research retrievals (discussed in Sect. 4) is based on published literature and the analysis of suborbital information on aerosol type presented in Sects. 3.1 and 3.2.

\section{The MISR aerosol research retrievals with inputs from field campaign data}

\subsection{Research retrieval details}

\subsubsection{Research retrieval theory}

In the MISR Research Aerosol Retrieval algorithm (Kahn et al., 2001; Kahn and Limbacher, 2012), the TOA radiation is simulated using a radiative transfer (RT) code developed by the MISR Team (Martonchik et al., 1998) that is based on the matrix operator method (Grant and Hunt, 1968). For a given aerosol particle analog, vertical distribution, sun and viewing geometry and surface reflectance properties, the RT code simulates the TOA radiances as would be observed by the MISR instrument. The radiances produced by up to four component aerosol particles are then weighted by their fractional contributions to the AOD to obtain the radiance of the aerosol mixture (Abdou et al., 1997). The over-land retrievals use all four MISR wavelengths. In the present study, MISR observations are simulated over MCMA. We assume 
a Rayleigh-scattering atmosphere with a surface pressure of $776 \mathrm{mb}$ (Mexico City is at an elevation of $\sim 2200 \mathrm{~m}$ ), and a standard mid-latitude temperature profile. The ozone abundance in the study area was obtained from Ozone Monitoring Instrument (OMI) data (Ahmad et al., 2003). The aerosols are assumed to be concentrated in a near-surface layer, except for medium-mode dust aerosols. The surface reflectance parameters are prescribed from the MISR Land Surface Product at each of the four MISR wavelengths, based on an analysis of the MISR surface retrieval record on low-AOD days, for the same viewing geometry and location of interest. In this case, the atmosphere is relatively cloud-free, the surface is reasonably well characterized, and the AOD is sufficient to provide a good atmospheric signal. These are reasonably good atmospheric conditions for remote-sensing aerosol retrievals.

The TOA simulated radiances are converted to TOA reflectance and compared to the MISR observed reflectance to determine the AOD and aerosol type. The agreement between simulated and observed TOA reflectance at all four wavelengths and at 9 viewing angles is assessed using three different Chi-Squared $\left(\chi_{\mathrm{abs}}^{2}, \chi_{\mathrm{geom}}^{2}, \chi_{\mathrm{spec}}^{2}\right)$ ) tests (Kahn et al., 2001). The largest of $\left(\chi_{\mathrm{abs}}^{2}, \chi_{\mathrm{geom}}^{2}, \chi_{\mathrm{spec}}^{2}\right)$ for a given mixture is designated as $\chi_{\max -3}^{2}$. The comparisons are made for all possible combinations of aerosol particles in different proportions (from 0 to $100 \%$ in increments of $5 \%$ ) within each four-component mixing group. In our study, the AOD for each combination is varied from 0.0 to 1.0 , in steps of 0.05 . We examined a hierarchy of relative and absolute acceptance criteria applied to ChiMin (the minimum value of $\chi_{\max -3}^{2}$ for all mixtures in a retrieval region), and looked for convergence toward a consistent result as more stringent criteria were applied. Kahn and Limbacher (2012) used similar criteria and provide further details on this approach. Unless specified otherwise, values shown in this paper are based on those retrievals meeting the $\chi_{\max -3}^{2}<$ ChiMin +0.1 criterion. For a given HR region, the mean values of aerosol properties (e.g., total AOD, small/medium/large mode and spherical/non-spherical AOD fractions, SSA, AE) from all mixtures that satisfy our $\chi_{\max -3}^{2}$ acceptance criteria are reported as successful retrievals and used in our analysis.

\subsubsection{Aerosol components and mixing groups}

Table 1 presents the four-component aerosol mixing groups. Table S2 lists the aerosol component particles that define the aerosol mixtures used in this study. Each of the 45 distinct aerosol components in Table S2 is defined by spectral real and imaginary indices of refraction and a lognormal size distribution, given as the particle geometric mean radius $\left(r_{\mathrm{pg}, \mathrm{N}}\right)$ and geometric standard deviation $\left(\sigma_{\mathrm{g}}\right)$. The optical properties for each spherical component are derived using a standard Mie scattering code, with the exception of the dust grains. The component particles represent biomass burning, urban pollution and dust aerosol particles that span five particles size ranges (very very small (VVS), very small (VS), small (S), medium (M) and large (L) particles) and four single scattering albedo ranges (very absorbing (VA), absorbing (A), less absorbing (LA) and weakly absorbing (WA) particles). For biomass burning particle analogs in Table $\mathrm{S} 2$, the sizes are: $\operatorname{VVS}\left(r_{\mathrm{pg}, \mathrm{N}}=0.04 \mu \mathrm{m}\right), \operatorname{VS}\left(r_{\mathrm{pg}, \mathrm{N}}=0.07 \mu \mathrm{m}\right)$, $\mathrm{S}\left(r_{\mathrm{pg}, \mathrm{N}}=0.13 \mu \mathrm{m}\right)$ and $\mathrm{S} 2\left(r_{\mathrm{pg}, \mathrm{N}}=0.16 \mu \mathrm{m}\right)$ and the midvisible SSA values are: A $\left(\omega_{0558}=0.84\right), \mathrm{LA}\left(\omega_{0558}=0.90\right)$ and WA $\left(\omega_{0558}=0.94\right)$. The sizes of the other spherical particle types that represent both pollution and biomass burning particle analogs (Table S2) are: VVS $\left(r_{\mathrm{pg}, \mathrm{N}}=0.06 \mu \mathrm{m}\right)$, VS $\left(r_{\mathrm{pg}, \mathrm{N}}=0.12 \mu \mathrm{m}\right), \mathrm{S}\left(r_{\mathrm{pg}, \mathrm{N}}=0.24 \mu \mathrm{m}\right), \mathrm{M}\left(r_{\mathrm{pg}, \mathrm{N}}=0.24 \mu \mathrm{m}\right)$ and $\mathrm{L}\left(r_{\mathrm{pg}, \mathrm{N}}=0.5 \mu \mathrm{m}\right)$ and the mid-visible SSA values are: VA $\left(\omega_{0558}=0.8\right), \mathrm{A}\left(\omega_{0558}=0.85\right), \mathrm{LA}\left(\omega_{0558}=0.9\right)$ and WA $\left(\omega_{0558}=0.95\right)$. Strong spectral dependence of aerosol absorption defines the "steep" particles that represent biomass burning aerosols, whereas the "flat" particles that represent pollution aerosols have spectrally independent absorption (Bond and Bergstrom, 2006).

Table 1 lists the 23 mixing groups used in this study. These mixtures are created to test the ability of the MISR algorithm to distinguish between sizes (M1-M4), steep and flat SSA spectral slope (M6, M7, M21), spherical and non-spherical (M10-M13), absorbing and non-absorbing (M14-M17) particles (Kahn et al., 2001). Based on the targeted tests, the mixing groups are collected into 10 larger groupings listed in column 1 of Table 1 . The last column in Table 1 provides a detailed description of the objective for each grouping. The mixing groups are created such that they span the range of sizes and optical properties of biomass burning, pollution and dust particles that were found in the MCMA during the INTEX-B field campaign.

\subsubsection{Research retrieval regions}

Figure 5 shows the area over which MISR research retrievals are performed in this study for 6 March. There are more than 400 individual retrieval regions in the retrieval area in Fig. 5. Research retrievals are performed over $825 \mathrm{~m} \times 825 \mathrm{~m}$ areas $(3 \times 3275 \mathrm{~m}$ MISR Local Mode radiance pixels) and this defines the retrieval regions in our case. We call these "high-resolution" retrievals when compared to the $17.6 \mathrm{~km} \times 17.6 \mathrm{~km}$ retrieval regions of the L2 MISR Standard aerosol product, and refer to them as HR regions in the paper. Note that the MISR instrument can be configured to provide high-resolution $(275 \times 275 \mathrm{~m})$ images in all 36 channels for targets and observation times selected several weeks in advance of the overpass. This capability is referred to as Local Mode. In the default Global Mode, all nadir cameras and all off nadir cameras for Red channels (Band 3) are kept at high resolution $(275 \mathrm{~m})$ whereas observations in the remaining 24 cameras are down-sampled onboard to $1.1 \mathrm{~km}$ (http://www-misr.jpl.nasa.gov/getData/localMode/). The locations of ground-based Microtops and AERONET stations are indicated as small white circles in Fig. 5. If ground observations of AOD are available at satellite overpass time, 
Table 1. Aerosol Mixing Groups.

\begin{tabular}{|c|c|c|c|c|c|c|}
\hline Groups & $\begin{array}{l}\text { Mixing } \\
\text { Groups }\end{array}$ & Component $1 *$ & Component 2 & Component 3 & Component 4 & Mixture Description \\
\hline Group 1 & $\begin{array}{l}\text { M1 } \\
\text { M2 } \\
\text { M3 } \\
\text { M4 }\end{array}$ & $\begin{array}{l}\text { p19 } \\
\text { p16 } \\
\text { p2 } \\
\text { p38 }\end{array}$ & $\begin{array}{l}\text { p29 } \\
\text { p20 } \\
\text { p4 } \\
\text { p39 }\end{array}$ & $\begin{array}{l}\text { p33 } \\
\text { p30 } \\
\text { p7 } \\
\text { p40 }\end{array}$ & $\begin{array}{l}\text { p37 } \\
\text { p34 } \\
\text { p10 } \\
\text { p41 }\end{array}$ & $\begin{array}{l}\text { These } 4 \text { mixtures have particles with a constant SSA but } \\
\text { different particles sizes. This group of mixtures (M1- } \\
\text { M4) tests the sensitivity of MISR algorithm to particle } \\
\text { size for our study and the most likely SSA in the study } \\
\text { area. The sizes are VVS, VS, S, M in the } 4 \text { mixtures } \\
\text { and the SSA of each mixture is LA, WA, LA, and Non- } \\
\text { absorbing respectively. }\end{array}$ \\
\hline Group 2 & M5 & p31 & p32 & p35 & p36 & $\begin{array}{l}\text { This mixture of VA and A type of S and M steep parti- } \\
\text { cles tests if a combination of size and SSA yields better } \\
\text { results compared to above group of mixtures with con- } \\
\text { stant SSA }\end{array}$ \\
\hline Group 3 & $\begin{array}{l}\text { M6 } \\
\text { M7 }\end{array}$ & $\begin{array}{l}\text { p17 } \\
\text { p21 }\end{array}$ & $\begin{array}{l}\text { p18 } \\
\text { p22 }\end{array}$ & $\begin{array}{l}\text { p19 } \\
\text { p23 }\end{array}$ & $\begin{array}{l}\text { p20 } \\
\text { p24 }\end{array}$ & $\begin{array}{l}\text { Mixture of Flat Small or Medium particles with differ- } \\
\text { ent SSA is used to test the sensitivity to distinguish pol- } \\
\text { lution from smoke particles }\end{array}$ \\
\hline Group 4 & $\begin{array}{l}\text { M8 } \\
\text { M9 }\end{array}$ & $\begin{array}{l}\text { p13 } \\
\text { p14 }\end{array}$ & $\begin{array}{l}\text { p27 } \\
\text { p20 }\end{array}$ & $\begin{array}{l}\text { p29 } \\
\text { p29 }\end{array}$ & $\begin{array}{l}\text { p15 } \\
\text { p33 }\end{array}$ & $\begin{array}{l}\text { These mixing groups test the likely SSA of parti- } \\
\text { cle sizes that produce acceptable results. Sensitivity to } \\
\text { steep and flat particles is also tested. }\end{array}$ \\
\hline Group 5 & $\begin{array}{l}\text { M10 } \\
\text { M11 }\end{array}$ & $\begin{array}{l}\text { p18 } \\
\text { p19 }\end{array}$ & $\begin{array}{l}\text { p22 } \\
\text { p33 }\end{array}$ & $\begin{array}{l}\text { p32 } \\
\text { p45 }\end{array}$ & $\begin{array}{l}\mathrm{p} 43 \\
-\end{array}$ & $\begin{array}{l}\text { Same as the above group of mixtures but with a dust } \\
\text { component ( } 2 \text { different sizes) added to the flat and steep } \\
\text { particles of different sizes }(\mathrm{S}, \mathrm{M}) \text {. }\end{array}$ \\
\hline Group 6 & $\begin{array}{l}\text { M12 } \\
\text { M13 }\end{array}$ & $\begin{array}{l}\text { p19 } \\
\text { p25 }\end{array}$ & $\begin{array}{l}\text { p33 } \\
\text { p29 }\end{array}$ & $\begin{array}{l}\text { p37 } \\
\text { p33 }\end{array}$ & $\begin{array}{l}\mathrm{p} 43 \\
\mathrm{p} 41\end{array}$ & $\begin{array}{l}\text { This group tests if dust can be replaced by a non- } \\
\text { absorbing medium sized particle. M } 12 \text { consists of dust } \\
\text { and M13 has a medium non-absorbing particle. }\end{array}$ \\
\hline Group 7 & $\begin{array}{l}\text { M14 } \\
\text { M15 } \\
\text { M16 } \\
\text { M17 }\end{array}$ & $\begin{array}{l}\text { p12 } \\
\text { p25 } \\
\text { p19 } \\
\text { p33 }\end{array}$ & $\begin{array}{l}\text { p15 } \\
\text { p29 } \\
\text { p40 } \\
\text { p37 }\end{array}$ & $\begin{array}{l}\mathrm{p} 33 \\
\mathrm{p} 42 \\
\mathrm{p} 41 \\
\mathrm{p} 42\end{array}$ & $\begin{array}{l}\mathrm{p} 41 \\
\mathrm{p} 43 \\
\mathrm{p} 42 \\
\mathrm{p} 43\end{array}$ & $\begin{array}{l}\text { This group of mixtures consists of particles with differ- } \\
\text { ent sizes and SSA and tests MISR algorithm's sensitiv- } \\
\text { ity to absorbing vs non-absorbing particles. }\end{array}$ \\
\hline Group 8 & $\begin{array}{l}\text { M18 } \\
\text { M19 } \\
\text { M20 }\end{array}$ & $\begin{array}{l}\mathrm{p} 2 \\
\mathrm{p} 2 \\
\mathrm{p} 3\end{array}$ & $\begin{array}{l}\mathrm{p} 4 \\
\mathrm{p} 4 \\
\mathrm{p} 5\end{array}$ & $\begin{array}{l}\mathrm{p} 7 \\
\mathrm{p} 6 \\
\mathrm{p} 8\end{array}$ & $\begin{array}{l}\text { p9 } \\
\text { p10 } \\
\text { p26 }\end{array}$ & $\begin{array}{l}\text { This group of mixtures consists of biomass burning } \\
\text { (BB) particles used by Chen et al. (2008). They are } \\
\text { used to test if the retrieval algorithm favors these par- } \\
\text { ticles over their spherical absorbing counterparts used } \\
\text { in groups } 1-7 \text {. The sensitivity to size and SSA of BB is } \\
\text { also tested in this group. }\end{array}$ \\
\hline Group 9 & M21 & $\mathrm{p} 2$ & p6 & p11 & $\mathrm{p} 18$ & $\begin{array}{l}\text { Mixture of BB and pollution like VVS and S particles } \\
\text { with LA and A SSA. Similar to group } 3 \text {, this group tests } \\
\text { the algorithm's sensitivity to distinguish pollution from } \\
\text { smoke particles }\end{array}$ \\
\hline Group 10 & $\begin{array}{l}\text { M22 } \\
\text { M23 }\end{array}$ & $\begin{array}{l}\mathrm{p} 2 \\
\mathrm{p} 1\end{array}$ & $\begin{array}{l}\mathrm{p} 9 \\
\mathrm{p} 2\end{array}$ & $\begin{array}{l}\text { p44 } \\
\text { p7 }\end{array}$ & $\begin{array}{l}- \\
\mathrm{p} 43\end{array}$ & Same as the group 5 but BB particles. \\
\hline
\end{tabular}

* The aerosol particle components (p1-p45) in columns 3-6 are described in Table S2.

their locations are indicated as red circles in Figs. 5a and 6a for 6 and 15 March, respectively. The HR region closest to the ground station having a valid AOD observation is indicated by a red-black circled dot in Figs. 5a and 6a. HSRL AOD along the flight track is also shown for 6 and 15 March in Figs. 5a and 6a, respectively. AOD comparisons are tabulated in Table 2. The following section discusses the MISR research retrieval results.

\subsection{MISR research retrievals over Mexico City Basin on 6 March 2006}

An analysis of the AOD and aerosol properties (shape, size, and SSA) from the MISR research retrieval algorithm, identifying aerosol air mass type, is presented here. Unless specified otherwise, the aerosol air mass and associated properties refer to MISR Research Algorithm retrievals. Figure 5 a shows the spatial distribution of $558 \mathrm{~nm}$ AOD from the MISR research algorithm, overlaid with $558 \mathrm{~nm}$ AOD from ground-based observations and $532 \mathrm{~nm}$ HSRL AOD. AOD 

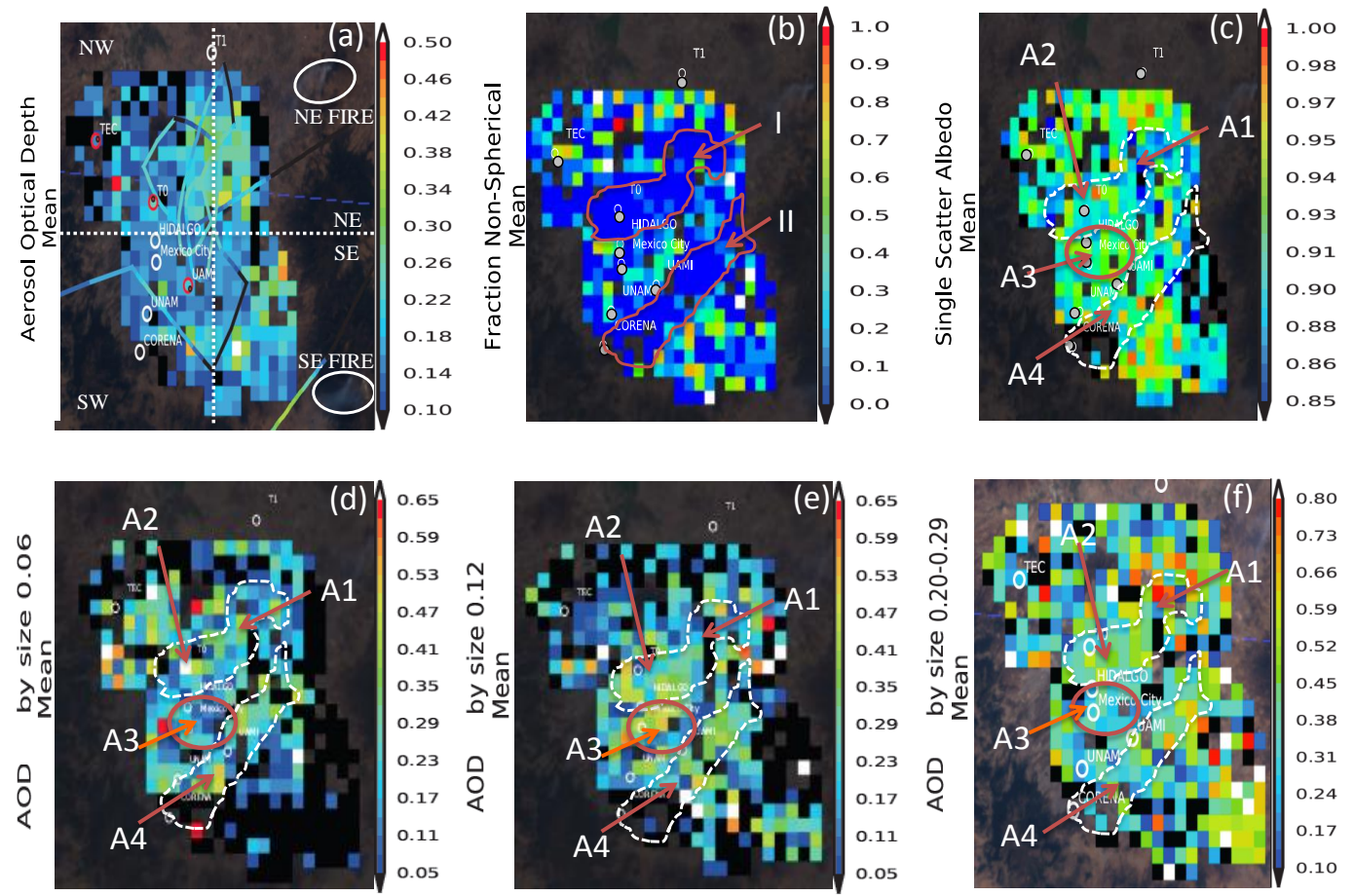

Fig. 5. Aerosol properties from MISR research retrieval algorithm over MCMA for 6 March 2006: (a) aerosol optical depth at $558 \mathrm{~nm}$ The HSRL $532 \mathrm{~nm}$ AOD along the flight path is superposed in panel (a). For HSRL, black color indicates missing data. (b) Non-spherical fraction of total AOD (c) Single Scattering Albedo at $558 \mathrm{~nm}$ (d) fraction of AOD by $0.06 \mu \mathrm{m}$ particles (e) fraction of AOD by $0.12 \mu \mathrm{m}$ particles (f) fraction of AOD by $0.2-0.28 \mu \mathrm{m}$ particles. (d, e, f) represent the small mode fraction of AOD. Distribution of large mode fraction of AOD is similar to (b). The 4 aerosol air masses identified by MISR are shown in (c, d, e, f).

from available coincident measurements are tabulated in Table 2. MISR AOD agrees to within 0.03 of Microtops AOD at UAMI and TEC. However, MISR AOD (0.13) is about half that at the T0 supersite $(0.25)$ in the central city. Given the low AOD (0.25) condition on this day, MISR research retrievals show ambiguity in the choice of particle size and SSA over the T0 site. This results in a large number of acceptable AOD retrievals that range from $0.05-0.3$, the mean of which is 0.13 . The higher AOD retrievals, however, correspond to mixtures comprising of VVS, VS and S particles and lower SSA $(\leq 0.80)$. HSRL AODs $(532 \mathrm{~nm})$ are within 0.05 of all ground-based AODs $(532 \mathrm{~nm}$ shown in bold in Table 2). Note that the HSRL extinction measurement starts at $300 \mathrm{~m}$ above ground level. The extinction from $300 \mathrm{~m}$ to ground is extrapolated assuming constant mixing ratio in the boundary layer, and then used to calculate the total column AOD. In this paper (e.g., in Table 2) we call this the HSRL AOD. AOD is also calculated at each of the vertical layers (30 m) using HSRL extinction measurements. We call the integrated layer AOD (without the AOD extrapolated below $300 \mathrm{~m}$ ) as LAOD in this paper. The LAOD is apportioned into different aerosol classes.

Figure $5 b$ shows the spatial distribution of the fraction of non-spherical particles in the aerosol mixtures that produce successful MISR AOD retrievals. The spatial distribution of
SSA and fraction of AOD attributable to $0.06,0.12$ and 0.22 $0.26 \mu \mathrm{m}$ sized particles in the aerosol mixtures are shown in Fig. 5c, d, e and f, respectively. The regions marked as I and II in Fig. 5b are dominated by spherical absorbing particles (analogs of smoke and pollution particles) uniformly, whereas other regions in the retrieval area consist of both spherical and non-spherical (dust analog) particles. The other aerosol properties (AOD, SSA and sizes) are less uniform in regions I and II and elsewhere. We identify four spatially distributed aerosol air masses that appear to have distinct aerosol properties in the MISR retrievals and for which coincident HSRL observations are available for evaluation. These aerosol air masses are marked in Fig. 5c-f, and their characteristics from MISR and HSRL are tabulated in Tables 3 and 4, respectively. According to MISR, aerosol air mass A1, which is downwind of the NE fires, consists predominantly of spherical, absorbing smoke particles from biomass burning. From Table 3 we see that A2, A3 and A4 are similar in terms of their SSA range and the percent contribution from 0.12 and 0.26 size particles, and the differences are within the range of measurement uncertainties. Aerosol type classifications from HSRL (see Table 4) also show more smoke $(\sim 55 \%)$ in $\mathrm{A} 1$ and more urban pollution particles in $\mathrm{A} 2$, A3 and A4 (41-52\%). HSRL data imply that the prevalent $0.26 \mu \mathrm{m}$ particles observed by MISR in A1 are analogs of 
Table 2. AOD (at $558 \mathrm{~nm}$ and $532 \mathrm{~nm}$ ) comparisons between MISR Level 2 (both standard and research retrievals) and other available ground based and aircraft instruments.

\begin{tabular}{|c|c|c|c|c|c|c|c|c|}
\hline Date & Site & Instrument & $\begin{array}{l}\text { Time }^{\mathrm{a}} \\
\text { (UTC) }\end{array}$ & $\begin{array}{l}\text { Distance } \\
\text { from Site }\end{array}$ & $\begin{array}{l}\text { AATS-14 } \\
\text { Pressure } \\
\text { Altitude }\end{array}$ & $\begin{array}{l}\text { Sub-orbital } \\
558 \text { AOD }(532 \\
\text { AOD) }\end{array}$ & MISR-R & MISR L2 \\
\hline \multirow[t]{10}{*}{ 6-Mar-06 } & \multirow{4}{*}{ UAMI } & Microtops & 17.33 & - & - & $0.21(\mathbf{0 . 2 2})$ & \multirow{4}{*}{$0.18(778 \mathrm{~m})$} & \multirow{4}{*}{-} \\
\hline & & & & & & & & \\
\hline & & $\mathrm{HSRL}^{\mathrm{c}}$ & 17.10 & $2.49 \mathrm{~km}$ & - & $-(0.19)$ & & \\
\hline & & AATS-14 & 17.28 & $2.74 \mathrm{~km}$ & $2.63 \mathrm{~km}$ & $0.13(\mathbf{0 . 1 5})$ & & \\
\hline & \multirow{3}{*}{ T0-AERONET } & CIMEL & 17.32 & - & - & $0.25(\mathbf{0 . 2 7})$ & \multirow{3}{*}{$0.13(550 \mathrm{~m})$} & \multirow{3}{*}{$0.10(9 \mathrm{~km})$} \\
\hline & & HSRL & 16.84 & $1.41 \mathrm{~km}$ & - & $-(0.21)$ & & \\
\hline & & AATS-14 & 17.47 & $230 \mathrm{~m}$ & $2.63 \mathrm{~km}$ & $0.11(\mathbf{0 . 1 3})$ & & \\
\hline & \multirow{3}{*}{ TEC } & Microtops & 17.33 & - & - & $0.13(\mathbf{0 . 1 5})$ & \multirow{3}{*}{$0.11(615 \mathrm{~m})$} & \multirow{3}{*}{$0.1(2.9 \mathrm{~km})$} \\
\hline & & HSRL & - & - & - & - & & \\
\hline & & AATS-14 & 16.8 & $5.65 \mathrm{~km}$ & $5.35 \mathrm{~km}$ & $0.005(\mathbf{0 . 0 0 5})$ & & \\
\hline \multirow[t]{14}{*}{ 15-Mar-06 } & \multirow{4}{*}{ UAMI } & Microtops & 17.25 & - & - & $0.40(\mathbf{0 . 4 3})$ & \multirow{4}{*}{$0.41(2.2 \mathrm{~km})$} & \multirow{4}{*}{$0.22(6.7 \mathrm{~km})$} \\
\hline & & & & & & & & \\
\hline & & HSRL & 17.18 & $4.2 \mathrm{~km}$ & - & $-(0.44)$ & & \\
\hline & & AATS-14 & 17.86 & $6 \mathrm{~km}$ & $4.9 \mathrm{~km}$ & $0.25(\mathbf{0 . 2 5})$ & & \\
\hline & \multirow{3}{*}{ HIDALGO } & Microtops & 17.25 & - & - & $0.54(\mathbf{0 . 5 8})$ & \multirow{3}{*}{$0.28(1.13 \mathrm{~km})$} & \multirow{3}{*}{$0.12(5.4 \mathrm{~km}$} \\
\hline & & HSRL & 17.16 & 1.63 & - & $-(0.47)$ & & \\
\hline & & AATS-14 & 17.25 & $922 \mathrm{~m}$ & $2.6 \mathrm{~km}$ & $0.19(\mathbf{0 . 2 0})$ & & \\
\hline & \multirow[t]{2}{*}{ UNAM } & Microtops & - & - & - & - & \multirow[t]{2}{*}{$\begin{array}{l}0.43 \\
(2.3 \mathrm{~km})\end{array}$} & \multirow[t]{2}{*}{ - } \\
\hline & & HSRL & 17.22 & $2.3 \mathrm{~km}$ & - & $-(0.32)$ & & \\
\hline & \multirow[t]{2}{*}{ CORENA } & Microtops & 17.7 & - & - & $\begin{array}{l}2.5 \\
\text { (anamolous) }\end{array}$ & \multirow[t]{2}{*}{-} & \multirow[t]{2}{*}{ - } \\
\hline & & HSRL & 17.36 & $1.75 \mathrm{~km}$ & - & 0.32 & & \\
\hline & \multirow{3}{*}{ T0-AERONET } & CIMEL & 17.48 & - & - & $0.41(\mathbf{0 . 4 4})$ & \multirow{3}{*}{$0.25(1.85 \mathrm{~km})$} & \multirow{3}{*}{$0.12(9.4 \mathrm{~km})$} \\
\hline & & HSRL & 17.14 & $42.6 \mathrm{~m}$ & - & $-(0.43)$ & & \\
\hline & & AATS-14 & 17.23 & $112 \mathrm{~m}$ & $2.63 \mathrm{~km}$ & $0.22(\mathbf{0 . 2 3})$ & & \\
\hline
\end{tabular}

a MISR overpass time is 17:37 UTC on 6 March 2006 and 17:26 UTC on 15 March 2006.

${ }^{\mathrm{b}}$ Distance of the aircraft measurement from the surface Site listed in column 2 . In the last two columns, values in parentheses are distances from the surface site to the center of the spacecraft retrieval region.

$\mathrm{c}$ The HSRL provides layer AOD $(\sim 0-\sim 7 \mathrm{~km}$ AGL $)$ unlike columnar measurements from sun photometers. HSRL AOD is at $532 \mathrm{~nm}$.

No AATS-14 observation over TEC ground site.

MISR-R is the AOD from MISR research retrieval algorithm averaged over all mixtures that pass the acceptance criteria, and correspondingly, MISR L2 is the standard MISR "best estimate" AOD product.

Note: sub-orbital AODs at $558 \mathrm{~nm}$ in column 7 are calculated using the angstrom formula

smoke particles and the smaller $0.12 \mu \mathrm{m}$ particles in $\mathrm{A} 2$ are better analogs of pollution particles. MISR retrievals over the central Mexico City area show that the aerosol air mass A3 is dominated by pollution particles $(0.12 \mu \mathrm{m})$ that are mixed with $\sim 35 \%$ dust. HSRL observations verify the presence of more urban (51\%) aerosols in A3 compared to A1, although the percent contribution of dusty mix to LAOD is similar (Table 4). Ground-based instruments that observed inorganic dust particles and sub-micron sized aerosols in the A3 area provide further validation of dust detected by MISR in A3. The broader size distribution of small particles in MISR re- trievals over A1, A2, and A4, however, is not supported by the HSRL data, which instead shows 39-45\% contribution from dusty mix type aerosols. However, it is noteworthy that HSRL may have only observed a portion of the aerosol air masses identified by MISR e.g., HSRL observed the rightmost edge of A3 where MISR does see up to $45 \%$ dust. Also note that the dusty mix HSRL classification is not pure dust and this identification occurs when depolarization measurements indicate the presence of dust with other components (particularly pollution vs. smoke) (Burton et al., 2012). Table 4 shows the uncertainty in AOD assigned to different 
Table 3. Characteristics of aerosol air masses based on shape, size and single scattering albedo as identified from the MISR research retrievals over the Mexico City metropolitan area.

\begin{tabular}{|c|c|c|c|c|c|c|c|c|c|c|}
\hline \multirow[b]{2}{*}{ Date } & \multirow{2}{*}{$\begin{array}{l}\text { Air Mass } \\
(\text { size })^{\mathrm{a}}\end{array}$} & \multirow[t]{2}{*}{ Shape } & \multirow{2}{*}{$\begin{array}{l}\text { AOD } \\
(558 \mathrm{~nm}) \\
\text { Range }\end{array}$} & \multicolumn{5}{|c|}{ Size $\left(r_{\text {eff }}\right.$ in $\left.\mu \mathrm{m}\right) \%$ Contribution } & \multirow{2}{*}{$\begin{array}{l}\text { SSA } \\
(558 \mathrm{~nm})\end{array}$} & \multirow[b]{2}{*}{ Comment } \\
\hline & & & & 0.06 & 0.12 & $0.22-0.26$ & 0.57 & 0.75 & & \\
\hline \multirow[t]{4}{*}{ 6-Mar-06 } & $\begin{array}{l}\text { A1 } \\
\left(\sim 75 \mathrm{~km}^{2}\right)\end{array}$ & Spherical & $0.25-0.35$ & $<25$ & $10-30$ & $30-80$ & - & - & $\begin{array}{l}0.85- \\
0.9\end{array}$ & $\begin{array}{l}\text { Region comprised of small } \\
\text { mode particles (reff }<0.26 \mu \mathrm{m} \text { ) }\end{array}$ \\
\hline & $\begin{array}{l}\text { A2 } \\
\left(\sim 50 \mathrm{~km}^{2}\right)\end{array}$ & Spherical & $0.1-0.25$ & 5-35 & 15-50 & 35-45 & $<20$ & - & $\begin{array}{l}0.9- \\
0.95\end{array}$ & $\begin{array}{l}\text { Region comprised of small (reff } \\
\leq 0.26 \mu \mathrm{m} \text { ) and medium (reff }= \\
0.57 \mu \mathrm{m}) \text { mode particles }\end{array}$ \\
\hline & $\begin{array}{l}\mathrm{A} 3 / \mathrm{MC}^{\mathrm{b}} \\
\left(\sim 35 \mathrm{~km}^{2}\right)\end{array}$ & $\begin{array}{l}\text { Spherical } \\
+ \text { Non- } \\
\text { spherical/ } \\
\text { Dust }\end{array}$ & $0.1-0.18$ & $<25$ & 15-50 & 25-35 & - & $10-40$ & $\begin{array}{l}0.9- \\
0.95\end{array}$ & $\begin{array}{l}\text { Region comprised of small (reff } \\
\leq 0.26 \mu \mathrm{m} \text { ) and large (reff }= \\
0.75 \mu \mathrm{m} \text { ) mode particles }\end{array}$ \\
\hline & $\begin{array}{l}\text { A4 } \\
\left(\sim 25 \mathrm{~km}^{2}\right)\end{array}$ & Spherical & $0.1-0.18$ & $<25$ & $\mathbf{2 0 - 4 0}$ & 15-35 & $<30$ & - & $\begin{array}{l}0.9- \\
0.95\end{array}$ & $\begin{array}{l}\text { Region comprised of small (reff } \\
\leq 0.26 \mu \mathrm{m}) \text { and medium }(\text { reff }= \\
0.57 \mu \mathrm{m}) \text { mode particles }\end{array}$ \\
\hline \multirow[t]{4}{*}{ 15-Mar-06 } & NE Quad & Spherical & $0.2-0.45$ & $<25$ & 10-50 & $10-45$ & $5-55$ & - & $0.9-1.0$ & $\begin{array}{l}\text { Region comprised of small (reff } \\
<0.26 \mu \mathrm{m} \text { ) and medium (reff }= \\
0.57 \mu \mathrm{m} \text { ) mode particles }\end{array}$ \\
\hline & NW Quad & Spherical & $0.2-0.35$ & $5-40$ & $5-50$ & $10-45$ & $<40$ & - & $\begin{array}{l}0.9- \\
0.95\end{array}$ & $\begin{array}{l}\text { Region comprised of small (reff } \\
\leq 0.26 \mu \mathrm{m} \text { ) and medium (reff }= \\
0.57 \mu \mathrm{m} \text { ) mode particles }\end{array}$ \\
\hline & SE Quad & Spherical & $0.1-0.3$ & $15-60$ & $<25$ & $<30$ & $<\mathbf{5 0}$ & - & $\begin{array}{l}0.88- \\
0.95\end{array}$ & $\begin{array}{l}\text { Region comprised of small } \\
(\text { reff } \leq 0.26 \mu \mathrm{m}) \text { and (reff } \\
<0.26 \mu \mathrm{m}) \text { mode particles } \\
\text { Note that the AODs closer to } \\
\text { Mexico City are cloud contam- } \\
\text { inated }\end{array}$ \\
\hline & SW Quad & $\begin{array}{l}\text { Spherical } \\
+ \text { Non- } \\
\text { spherical/ } \\
\text { Cirrus }\end{array}$ & $\begin{array}{l}\text { Cloud Con- } \\
\text { taminated }\end{array}$ & - & - & - & - & - & - & Cirrus clouds found in this area \\
\hline
\end{tabular}

a This is the approximate size of the aerosol air mass. The aerosol air mass sizes were estimated based on visual reading of the number of pixels (that fell within each air mass we identified) multiplied by size of single retrieval pixel.

${ }^{\mathrm{b}} \mathrm{MC}=$ Mexico City.

Note: numbers in bold highlight the particle sizes in each mixture that makes highest \% contribution to the total AOD.

Table 4. Characteristics of aerosol air masses from HSRL data over the Mexico City metropolitan area. These air masses correspond to the air masses identified by MISR in Table 5.

\begin{tabular}{lcrrr}
\hline Air mass & $\begin{array}{r}\text { HSRL-AOD Range } \\
\text { over each air mass }\end{array}$ & $\begin{array}{r}\text { \%DUST- AOD } \\
\text { (Uncertainty) }\end{array}$ & $\begin{array}{r}\text { \%Smoke-AOD } \\
\text { (Uncertainty) }\end{array}$ & $\begin{array}{r}\text { \%Urban-AOD } \\
\text { (Uncertainty) }\end{array}$ \\
\hline A1 & $0.14-0.30$ & $37 \%(7 \%)$ & $55 \%(10 \%)$ & $4 \%(1 \%)$ \\
A2 & $0.21-0.25$ & $45 \%(19 \%)$ & $3 \%(1.5 \%)$ & $52 \%(22 \%)$ \\
A3 & $0.19-0.25$ & $38 \%(15 \%)$ & $10 \%(4 \%)$ & $50 \%(20 \%)$ \\
A4 & $0.18-0.25$ & $39 \%(9 \%)$ & $14 \%(3 \%)$ & $41 \%(9 \%)$ \\
\hline
\end{tabular}

Note: (1) The DUST in column 3 pertains to both "dusty mix" and pure dust. The dusty mix identification occurs when depolarization measurements indicate the presence of dust with other components (particularly pollution vs. smoke) (Burton et al., 2012). (2) Smoke pertains to both smoke and fresh smoke classes (3) \% Contribution of Smoke, Dust and Urban AOD values are weighted mean values (weighted by AOD). The percentage in brackets indicate the uncertainty in \%contribution for the given aerosol type. This is the uncertainty due to the fraction of total AOD that remains unclassified from extinction measurements below $300 \mathrm{~m}$.

aerosol classes. We calculate the uncertainty value by considering HSRL AOD as the total AOD instead of the LAOD; this accounts for unclassified near-surface AOD and provides the lower limit on the calculations. However, as this location is a source region for pollution particles, the near-surface component is likely to contain a larger fraction of such particles than the total column. Also, note that MISR is generally not sensitive to the properties of aerosol components that contribute $<20 \%$ to the total AOD (Kahn et al., 2001), which in this case could include the dust component reported by the HSRL over A2 and A4, where MISR detects up to 20 and $30 \%$ medium sized particles but no dust. 

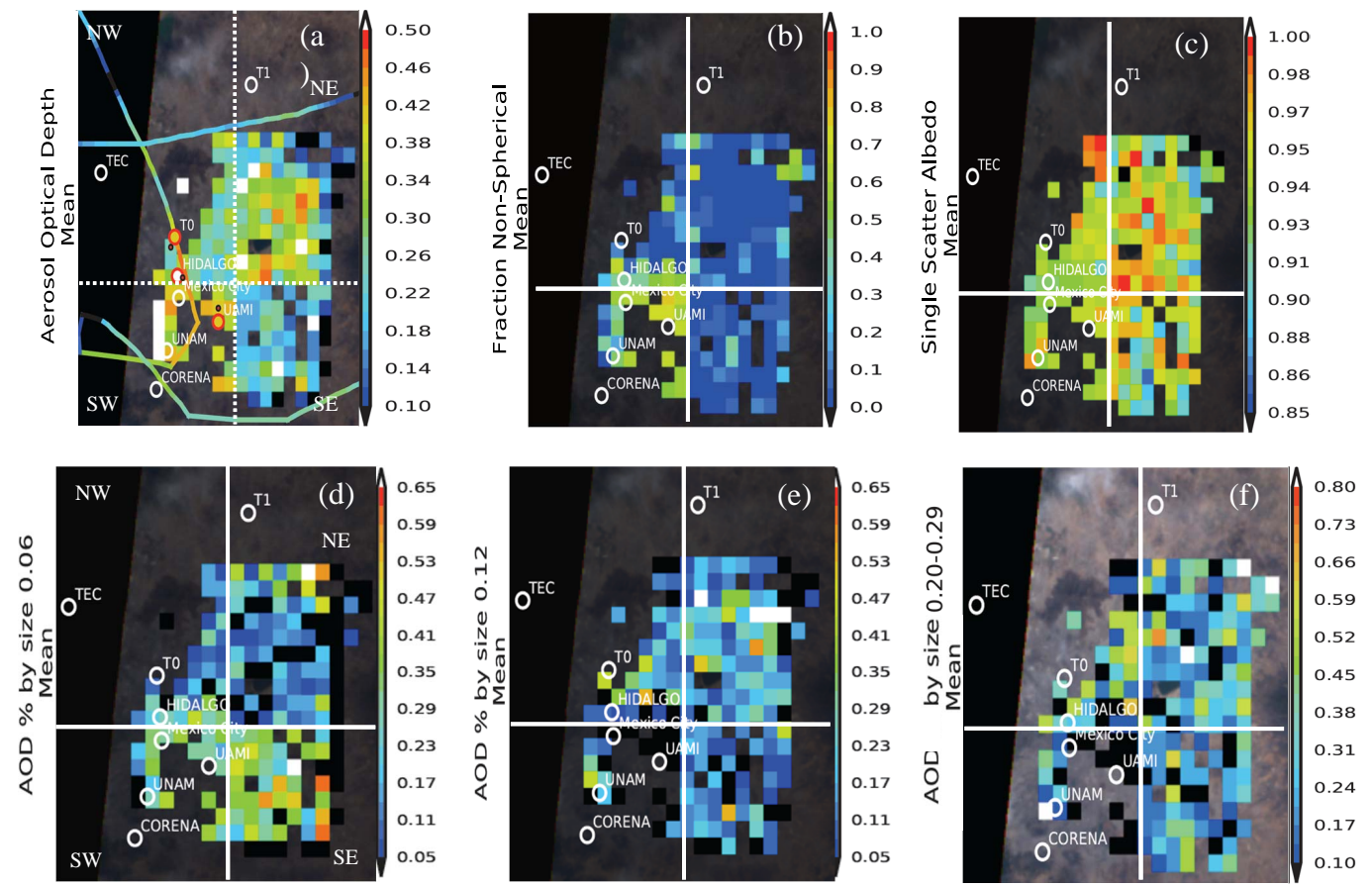

Fig. 6. Aerosol properties from MISR research retrieval algorithm over MCMA on 15 March 2006: (a) aerosol optical depth at $558 \mathrm{~nm}$. The HSRL $532 \mathrm{~nm}$ AOD along the flight path is superposed in panel (a). For HSRL, black color indicates missing data (b) non-spherical fraction of AOD (c) Single Scattering Albedo at $558 \mathrm{~nm}$ (d) fraction of AOD by size $0.06 \mu \mathrm{m}$ (e) fraction of AOD by size $0.12 \mu \mathrm{m}$ (f) fraction of AOD by size $0.26 \mu \mathrm{m}$. (d, e, f) represent the small mode fraction of AOD. Distribution of large mode fraction of AOD is similar to (b).

The comparison of aerosol properties from MISR against sub-orbital HSRL observations illustrates the capability of MISR to qualitatively distinguish aerosol air masses in the MCMA, and suggests that the relative differences in small vs. coarse mode particles in the four aerosol air masses are robust. From the comparisons with HSRL we find that on this day, of the four air masses (A1-A4), MISR is able to distinguish two air mass types in the study region based solely on particle microphysical properties - one dominated by smoke particles (A1) and the others that are mixtures of smoke, pollution and/or dust particles (A2-A4). And as expected, the aerosol type information from MISR, although significant, must be viewed as qualitative.

\subsection{MISR research retrievals over Mexico City basin on 15 March 2006}

Figure 6a shows the mid-visible AOD retrieved by the MISR research algorithm in our study region on 15 March 2006. AOD ranges between 0.15 and 0.5 , higher than that on 6 March (Fig. 5a). The MISR L1B true-color image in Fig. 1b shows more smoke from fires surrounding the Mexico City basin on this day than on 6 March (compare Fig. 1a, b), and a mixture of clouds and fires in the western half of the study region. Note that MISR cannot perform aerosol retrievals over cloud-covered regions. A gradient can be seen in both AOD and MISR particle property maps in Fig. 6. In the northern half of the figure, there is an east-west gradient in the AOD that is likely due to varying concentrations of biomass burning aerosols from the fires on the NE side of the Mexico City basin. Northerly winds as high as $15 \mathrm{~m} \mathrm{~s}^{-1}$ were observed in the area on 15 March (Fast et al., 2007). Gradients in AOD in the SE quadrant also corroborate the gradient in smoke concentration seen qualitatively in Fig. 1b. Where available, the retrieved AOD comparison to ground-based AOD is shown in Fig. 6a (red circles). At MISR overpass time (17:26 UTC), a gradient in AOD is also reflected in the surface measurements, with higher AOD at Hidalgo (0.54) than at the T0 (0.4) or UAMI (0.41) sites. Hidalgo is closer to Mexico City, whereas T0 is to the north, and UAMI is to the southeast, as shown in Fig. 6, providing qualitative verification of the MISR-retrieved AOD pattern. Near-coincident HSRL observations provide further validation, with higher AOD (0.47) in the city (near Hidalgo) and lower AOD outside the city $(\mathrm{AOD}=0.43$ at $\mathrm{T} 0$ and 0.32 at TEC and UNAM/Corena) (see Table 2 for AOD comparisons). At UAMI, the MISR AOD (0.41) is in good agreement with the Microtops and HSRL AODs (0.40, 0.44 respectively), whereas at other ground sites, MISR AOD is cloud contaminated (see Fig. 1b. Notice the differences in the locations of clouds relative to the surface in the forward 
and aft camera views that resulted in the cloud-contaminated retrievals).

Returning to Fig. 6b, the fraction AOD non-spherical is higher (50-80\%) around central Mexico City and lower (generally $<10 \%$ ) elsewhere. This is due to the presence of the thin patchy cirrus clouds at high altitudes $(>9.5 \mathrm{~km}$ a.s.1.) in the region, as confirmed by the J31 and B200 aircraft field catalogs (http://catalog.eol.ucar.edu/cgi-bin/milagro/report/ index). Examination of cirrus reflectance from MODIS also indicates the presence of thin localized cirrus clouds over the central city. However, the HSRL aerosol classification in the SW quadrant indicates that urban aerosols made the greatest contribution to AOD over the city, whereas a mixture of dust and urban aerosols were the dominant retrieved AOD components outside the city (Fig. 4). In other parts of the study area (NW, NE and SE quadrants), the particle properties agree qualitatively with the presence of smoke, as observed by MISR (see Fig. 1b). The research algorithm favors $\sim 50 \%$ VVS and $\sim 30 \%$ VS sized biomass burning aerosols in the NE quadrant. The HSRL transect to the north also shows $>55 \%$ smoke in this region (classification in this region not shown in Fig. 4). SSA co-varies with AOD, similar to $6 \mathrm{March}$. However, the aerosol air masses in the study area are, in general brighter (higher SSA) on 15 March. Regions dominated by biomass burning aerosols (e.g., NW quadrant) might have different SSA values due to the burning of different fuel types or the presence of biomass burning aerosols from different fire stages (e.g., flaming vs. smoldering) (Rei et al., 2005) on the two days. Aiken et al. (2010) mention that the fires were somewhat more intense in early March. Also, during the first 13 days of the field campaign (1-13 March 2006) the surface conditions in MCMA were usually dry, with less than $10 \%$ relative humidity $(\mathrm{RH})$ in the afternoon. A cold surge during 14-15 March increased the RH to $40 \%$ at the surface and $60 \%$ at $\sim 3 \mathrm{~km}$ (Fast et al., 2007) where smoke aerosols were found. Higher RH at the altitude with smoke ( 3 and $4 \mathrm{~km}$ ) can also result in hygroscopic growth of the aerosols, contributing to higher SSA on 15 March.

Based on the comparisons of MISR research retrievals against sub-orbital data, we confirm that MISR can distinguish aerosol air masses qualitatively, based on shape, size and SSA. From MISR research retrievals, the following conclusions are drawn about the two case study days. We see different aerosol air masses on each day. On both days, spherical absorbing particles dominate over non-absorbing ones, although there is regional variation in this. The size of the dominant absorbing $(\mathrm{SSA}=0.85)$ particles is smaller $\left(r_{\mathrm{eff}}=\right.$ $0.06 \mu \mathrm{m})$ on 6 March compared to $15 \operatorname{March}\left(r_{\mathrm{eff}}=0.12 \mu \mathrm{m}\right)$. Except for the central Mexico City area (SW quadrant), there is more dust on 6 March relative to 15 March. This result is confirmed by HSRL observations. Drier conditions on 6 March favor the presence of more dust. Spherical absorbing particles having steeply sloping spectral absorption (smokelike) are favored more than their flat (pollution-like) counterparts on both the days. Smoke and pollution particles are dis- tinguished based on particle size. SSA from both AERONET and MISR research retrievals suggest that, on an average, the aerosol air masses are brighter (higher SSA) on 15 March.

\subsection{Analysis of MISR L2 standard aerosol product over our study region}

The MISR L2 standard AOD in the MCMA (our study area) was higher than the surrounding regions on both 6 and 15 March 2006. AOD in MCMA is higher on 15 March than on $6 \mathrm{March}$, all in agreement with sub-orbital and research retrievals. However, the AOD on both days is lower than all the in-situ observations used in this study. AOD was not retrieved over a few regions within MCMA that resulted in either fill values (from neighboring retrievals) or no reported AOD values. We further investigated the performance of the MISR standard aerosol retrieval algorithm over MCMA by looking closely at the retrieval diagnostic parameters and indicators reported for each $17.6 \times 17.6 \mathrm{~km}$ retrieval region in the L2 Aerosol product. Successful aerosol retrievals identified primarily large and small/medium spherical non-absorbing particle mixtures. Mixtures containing dust were selected in few other instances. In one instance, the standard algorithm picked dust mixtures on 15 March in regions where thin cirrus clouds were present. When the retrieved AOD was very low $(<0.05)$, a large number of successful mixtures $(>50)$ contributed towards the regional best estimate AOD. As discussed by Kahn et al. (2010), we find that in the urban environment of Mexico City, the standard MISR algorithm tends to pick mixtures with high single scattering albedo $\left(\mathrm{SSA}_{558}=1.0\right)$, resulting in an underestimation of AOD. The Regional Class Indicator flag shows that retrievals were not attempted over regions flagged as topographically complex. Retrieval flags (RetrAppMask) for regions with no L2 AOD retrievals also show that over most of these regions, retrievals failed due to poor correlation of the equivalent reflectance spatial distribution from one MISR view angle to another. Poor angle-to-angle correlation can result from features such a complex terrain, aerosol plume edges, cloud edges, cloud shadows, and unscreened glint regions. We further investigated the diagnostic flags for six months of MISR L2 data for the same spacecraft paths (P026, P025) as the 6 and 15 March observations, and find the above patterns to hold true for all L2 retrievals over our study region having similar viewing geometry. The feasibility of retrieving AOD using the research retrieval algorithm and better agreement of AOD and aerosol properties with validation data indicates that the heterogeneity in aerosol particle type and aerosol loading over the $17.6 \times 17.6 \mathrm{~km}$ retrieval regions of the MISR standard algorithm, the presence of very dark pollution particles $\left(\mathrm{SSA}_{558}=0.7\right)$ in MCMA, complex topography and the vertical distribution of aerosols (smoke at $\sim 4 \mathrm{~km}$ ) limit the retrieval results from the MISR standard algorithm. This suggests the need to include darker pollution-like particles and 
to perform higher spatial resolution retrievals with the MISR observations for urban regions such as Mexico City.

\section{Summary and conclusions}

In this study, we have assessed the ability of the MISR Research aerosol retrieval algorithm to distinguish different aerosol air mass types in the Mexico City Metropolitan Area on two days, 6 and 15 March 2006, during the INTEX-B field campaign for which we have coincident, ground-based and aircraft observations. Additionally, the MISR Research retrieval results were used to evaluate the performance of the MISR V22 Standard aerosol retrieval algorithm in our study area. Comparison of aerosol properties retrieved from MISR against the sub-orbital HSRL verify the ability of MISR to distinguish qualitatively between different aerosol air masses in MCMA. Both MISR and sub-orbital observations suggest the presence of mixtures of dust, biomass burning and urban aerosols in the study area. We summarize the findings from the MISR Research retrieval algorithm here.

- In MCMA, MISR AOD shows regional variability at $<17.6 \mathrm{~km}$ scales on both 6 and 15 March 2006. The AOD and its variability are lower on 6 March than on 15 March. Sub-orbital measurements confirm these results and also provide qualitative verification of the MISR retrieved AOD pattern in the study area. Local meteorology governs the distribution of aerosols in MCMA. The basin-scale circulations on our case study days are found to be climatologically representative.

- On the two study days, the MISR research algorithm cannot distinguish between weakly absorbing and nonabsorbing particles. The weakly absorbing $\left(\omega_{0558}=\right.$ $0.95)$ spherical particles in mixtures were found to be replaceable by non-absorbing $\left(\omega_{0558}=1.0\right)$ spherical particles in the retrievals. In regions where dust particles were picked more frequently by the research algorithm, the dust particle $\left(r_{\text {eff }}=0.75 \mu \mathrm{m} ; \omega_{0} 558=0.97\right)$ could be substituted by a larger non-spherical red-dust (ellipsoidal) particle $\left(r_{\text {eff }}=1.18 \mu \mathrm{m}\right)$ with a lower SSA (0.88). Based on earlier sensitivity studies (Kahn et al., 2001; Kalashnikova and Kahn, 2006), this is expected, though this detail is specific to a complex urban environment such as MCMA.

- In situations such as on 6 and 15 March 2006, when aerosols from local pollution mix with transported biomass burning aerosol from fires on adjacent mountains, the MISR research algorithm could not distinguish between particles that show steep vs. flat spectral behavior of aerosol absorption or SSA (i.e., smoke vs. pollution). However, urban and smoke aerosols are distinguished based on particle size, as confirmed by suborbital validation data.
- For HR retrievals in this study, obtaining robust results from the research algorithm over the fire plumes to the east of Mexico City was difficult, because the plume appeared to move relative to the ground as the camera angle changed due to plume height, and the plumes were too small to co-register consistently at higher elevations. This also made the relative abundance of spherical vs. non-spherical particles difficult to constrain at locations where discrete, elevated smoke plumes features were in the FOV of some of the MISR cameras. High-altitude cirrus clouds posed similar challenges on 15 March (as also discussed by Pierce et al., 2010).

- Detailed analysis of MISR research retrieval results suggests that two distinct aerosol air mass types were identified based solely on particle microphysical properties, over the Mexico City metropolitan area: one dominated by smoke and another consisting of a mixture of smoke, dust and pollution particles. In general, $>70 \%$ of the AOD was attributed to spherical absorbing particles and up to $15 \%$ to spherical non-absorbing particles. Non-spherical particle dust analogs contributed up to $30 \%$. The gradients in the particle properties agree qualitatively with HSRL in most cases.

In summary, over an urban area, surface heterogeneity, lack of specific knowledge about particle microphysical properties, limited angular sampling, poorly constrained aerosol vertical distribution, coupled with low AOD conditions (as on 6 March) can make it difficult to constrain particle properties. MISR research retrievals from this study demonstrate that over MCMA, MISR can distinguish at least two aerosol modes (fine and medium/coarse), and that fine mode $(<0.26$ micron) spherical absorbing aerosols are dominant in the region during our study period. MISR retrievals cannot tell with confidence the difference between medium mode and coarse mode aerosol types in relatively low AOD situations over bright and varying urban surfaces. The distinction between urban and biomass burning aerosols under these circumstances is made based on particle size, though not on particle SSA or its spectral slope, though such distinctions may be possible under more favorable retrieval conditions. Taken together, MISR was able to aptly distinguish regions dominated by dust, smoke and/or urban aerosols for our study days. Taking advantage of over $13 \mathrm{yr}$ of global observations from MISR, our future work will focus on mapping the seasonal and inter-annual history of aerosol air mass type and AOD gradients for mega-city environments globally.

\section{Supplementary material related to this article is available online at http://www.atmos-chem-phys.net/13/ 9525/2013/acp-13-9525-2013-supplement.pdf.}


Acknowledgements. We acknowledge the collaborative effort of a large number of participants and multi-national agencies that contributed to the MILAGRO/INTEX-B Campaign. We gratefully acknowledge the NASA Langley Flight Research Service Directorate for their support of B200 flight operations during MILAGRO. Support for the HSRL deployment during MILAGRO and the analyses of these data was provided by the NASA Science Mission Directorate, the NASA CALIPSO project, and the Office of Science (BER), US Department of Energy (Atmospheric Science Program), Interagency Agreement No. DE-AI02-05ER6398. We also acknowledge AERONET site managers at Mexico City A. Leyva, Technician H. R. Estèvez from the Institute of Geophysics at UNAM and the AERONET global PI, B. Holben, for making available an extensive and high quality aerosol data set, and the AATS-14 instrument team, led by Jens Redemann. We thank the PIs of various instruments at the five ground sites (Hidalgo, Mexico City, UNAM, UAMI and Corena). Size distribution, meteorological, and aerosol optical depth data from these sites were used to evaluate MISR retrievals. Special thanks to Bob Yokelson for helpful discussions about the fires during our study period, and to B. De Foy for insights about the relative humidity data. Thanks also to $\mathrm{S}$. Madronich, L. Molina, and J. Meitin for their dedication in making the MILAGRO campaign a success for all. The work of R. Kahn is supported in part by NASA's Climate and Radiation Research and Analysis Program under H. Maring, NASA's Atmospheric Composition Program under R. Eckman, which also supported F. Patadia, and the NASA Earth Observing System MISR instrument project.

Edited by: E. Gerasopoulos

\section{References}

Abdou, W. A., Diner, D. J., Martonchik, J. V., Bruegge, C. J., Kahn, R. A., Gaitley, B. J., Crean, K. A., Remer, L. A., and Holben, B.: Comparison of coincident Multiangle Imaging Spectroradiometer and Moderate Resolution Imaging Spectroradiometer aerosol optical depths over land and ocean scenes containing Aerosol Robotic Network sites, J. Geophys. Res.-Atmos., 110, D10S07, doi:10.1029/2004JD004693, 2005.

Ahmad, S. P., Levelt, P. F., Bhartia, P. K., Hilsenrath, E., Leppelmeier, G. W., and Johnson, J. E.: Atmospheric products from the ozone monitoring instrument (OMI), Proc. SPIE 5151, 619, doi:10.1117/12.506042, 2003.

Aiken, A. C., de Foy, B., Wiedinmyer, C., DeCarlo, P. F., Ulbrich, I. M., Wehrli, M. N., Szidat, S., Prevot, A. S. H., Noda, J., Wacker, L., Volkamer, R., Fortner, E., Wang, J., Laskin, A., Shutthanandan, V., Zheng, J., Zhang, R., Paredes-Miranda, G., Arnott, W. P., Molina, L. T., Sosa, G., Querol, X., and Jimenez, J. L.: Mexico city aerosol analysis during MILAGRO using high resolution aerosol mass spectrometry at the urban supersite (T0) Part 2: Analysis of the biomass burning contribution and the non-fossil carbon fraction, Atmos. Chem. Phys., 10, 5315-5341, doi:10.5194/acp-10-5315-2010, 2010.

Bergstrom, R. W., Schmidt, K. S., Coddington, O., Pilewskie, P., Guan, H., Livingston, J. M., Redemann, J., and Russell, P. B.: Aerosol spectral absorption in the Mexico City area: results from airborne measurements during MILAGRO/INTEX B, At- mos. Chem. Phys., 10, 6333-6343, doi:10.5194/acp-10-63332010, 2010.

Bond, T. C. and Bergstrom, R. W.: Light Absorption by Carbonaceous Particles: An Investigative Review, Aerosol Sci. Technol., 40, 27-67, doi:10.1080/02786820500421521, 2006.

Burton, S. P., Ferrare, R. A., Hostetler, C. A., Hair, J. W., Rogers, R. R., Obland, M. D., Butler, C. F., Cook, A. L., Harper, D. B., and Froyd, K. D.: Aerosol classification using airborne High Spectral Resolution Lidar measurements - methodology and examples, Atmos. Meas. Tech., 5, 73-98, doi:10.5194/amt-5-73-2012, 2012.

Chen, W. T., Kahn, R. A., Nelson, D., Yau, K., and Seinfeld, J. H.: Sensitivity of multiangle imaging to the optical and microphysical properties of biomass burning aerosols. J. Geophys. Res., 113, D10203, doi:10.1029/2007JD009414, 2008.

Corr, C. A., Krotkov, N., Madronich, S., Slusser, J. R., Holben, B., Gao, W., Flynn, J., Lefer, B., and Kreidenweis, S. M.: Retrieval of aerosol single scattering albedo at ultraviolet wavelengths at the T1 site during MILAGRO, Atmos. Chem. Phys., 9, 58135827, doi:10.5194/acp-9-5813-2009, 2009.

de Almeida Castanho, A. D., Prinn, R., Martins, V., Herold, M., Ichoku, C., and Molina, L. T.: Analysis of Visible/SWIR surface reflectance ratios for aerosol retrievals from satellite in Mexico City urban area, Atmos. Chem. Phys., 7, 5467-5477, doi:10.5194/acp-7-5467-2007, 2007.

de Foy, B., Fast, J. D., Paech, S. J., Phillips, D., Walters, J. T., Coulter, R. L., Martin, T. J., Pekour, M. S., Shaw, W. J., Kastendeuch, P. P., Marley, N. A., Retama, A., and Molina, L. T.: Basinscale wind transport during the MILAGRO field campaign and comparison to climatology using cluster analysis, Atmos. Chem. Phys., 8, 1209-1224, doi:10.5194/acp-8-1209-2008, 2008

de Foy, B., Burton, S. P., Ferrare, R. A., Hostetler, C. A., Hair, J. W., Wiedinmyer, C., and Molina, L. T.: Aerosol plume transport and transformation in high spectral resolution lidar measurements and WRF-Flexpart simulations during the MILAGRO Field Campaign, Atmos. Chem. Phys., 11, 3543-3563, doi:10.5194/acp-11-3543-2011, 2011.

Dubovik, O. and King, M. D.: A flexible inversion algorithm for retrieval of aerosol optical properties from Sun and sky radiance measurements, J. Geophys. Res., 105, 20673-20696, 2000.

Eck, T. F., Holben, B. N., Reid, J. S., Dubovik, O., Smirnov, A., O'Neill, N. T., Slutsker, I., and Kinne, S.: Wavelength dependence of the optical depth of biomass burning, urban, and desert dust aerosols, J. Geophys. Res., 104, 31333-31349, doi:10.1029/1999JD900923, 1999.

Fast, J. D., de Foy, B., Acevedo Rosas, F., Caetano, E., Carmichael, G., Emmons, L., McKenna, D., Mena, M., Skamarock, W., Tie, X., Coulter, R. L., Barnard, J. C., Wiedinmyer, C., and Madronich, S.: A meteorological overview of the MILAGRO field campaigns, Atmos. Chem. Phys., 7, 2233-2257, doi:10.5194/acp-7-2233-2007, 2007.

Grant, I. P. and Hunt, G. E.: Descrete space theory of radiative transfer - I. Fundamentals, Proc. Roy. Soc. Lond.A, 313, 183-197, 1969.

Holben, B. N., Eck, T. F., Slutsker, I., Tanre, D., Buis, J. P., Setzer, A., Vermote, E., Reagan, J. A., Kaufman, Y. J., Nakajima, T., Lavenu, F., Jankowiak, I., and Smirnov, A.: AERONET - A federated instrument network and data archive for aerosol characterization, Remote Sens. Environ., 66, 1-16, 1998. 
Holben, B. N., Tanre, D., Smirnov, A., Eck, T. F., Slutsker, I., Abuhassan, N., Newcomb, W. W., Schafer, J., Chatenet, B., Lavenue, F., Kaufman, Y. J., Vande Castle, J., Setzer, A., Markham, B., Clark, D., Frouin, R., Halthore, R., Karnieli, A., O’Neill, N. T., Pietras, C., Pinker, R. T., Voss, K., and Zibordi, G.: An emerging ground-based aerosol climatology: Aerosol Optical Depth from AERONET, J. Geophys. Res., 106, 12067-12097, 2001.

Ichoku C., Levy, R., Kaufman, Y. J., Remer, L. A., Li, R. -R., Martins, V. J., Holben, B. N., Abuhassan, N., Slutsker, I., Eck, T. F., and Pietras, C.: Analysis of the performance characteristics of the five-channel Microtops II sun photometer for measuring aerosol optical thickness and precipitable water vapor, J. Geophys. Res., 107, doi:10.1029/2001JD001302, 2002.

IPCC, 2007: Climate Change 2007: The Physical Science Basis. Contribution of Working Group I to the Fourth Assessment Report of the Intergovernmental Panel on Climate Change, edited by: Solomon, S., Qin, D., Manning, M., Chen, Z., Marquis, M., Averyt, K. B., Tignor, M., and Miller, H. L., Cambridge University Press, Cambridge, United Kingdom and New York, NY, USA, 2007.

Kahn, R. A. and Limbacher, J.: Eyjafjallajökull volcano plume particle-type characterization from space-based multi-angle imaging, Atmos. Chem. Phys., 12, 9459-9477, doi:10.5194/acp12-9459-2012, 2012.

Kahn, R., Banerjee, P., and McDonald, D.: Sensitivity of multiangle imaging to natural mixtures of aerosols over ocean, J. Geophys. Res., 106, 18219-18238, doi:10.1029/2000JD900497, 2001.

Kahn, R. A., Gaitley, B. J., Martonchik, J. V., Diner, D. J., Crean, K. A., and Holben, B. N.: Multiangle Imaging Spectroradiometer (MISR) global aerosol optical depth validation based on 2 years of coincident Aerosol Robotic Network (AERONET) observations, J. Geophys. Res., 110, D10S04, doi:10.1029/2004JD004706, 2005.

Kahn, R., Petzold, A., Wendisch, M., Bierwirth, E., Dinter, T., Esselborn, M., Fiebig, M., Heese, B., Knippertz, P., Muller, D., Schladitz, A., and von Hoyningen-Huene, W.: Desert Dust Aerosol Air Mass Mapping in the western Sahara, Using particle properties derived from space-based multi-angle imaging, Tellus, 61B, 239-251, doi:10.1111/j.1600-0889.2008.00398.x, 2009a.

Kahn, R. A., Nelson, D. L., Garay, M., Levy, R. C., Bull, M. A., Diner, D. J., Martonchik, J. V., Paradise, S. R., and Hansen, E. G., and Remer, L. A.: MISR Aerosol product attributes, and statistical comparisons with MODIS, IEEE Trans. Geosci. Remt. Sens., 47, 4095-4114, 2009b.

Kahn, R. A., Gaitley, B. J., Garay, M. J., Diner, D. J., Eck, T. F., Smirnov, A., and Holben B. N.: Multiangle Imaging SpectroRadiometer global aerosol product assessment by comparison with the Aerosol Robotic Network, J. Geophys. Res., 115, D23209, doi:10.1029/2010JD014601, 2010.

Kalashnikova, O. V. and Kahn R. A.: Ability of multiangle remote sensing observations to identify and distinguish mineral dust types: 2. Sensitivity over dark water, J. Geophys. Res.-Atmos., 111, D11207, doi:10.1029/2008JD010083, 2006.

Kleinman, L. I., Springston, S. R., Wang, J., Daum, P. H., Lee, Y.-N., Nunnermacker, L. J., Senum, G. I., Weinstein-Lloyd, J., Alexander, M. L., Hubbe, J., Ortega, J., Zaveri, R. A., Canagaratna, M. R., and Jayne, J.: The time evolution of aerosol size distribution over the Mexico City plateau, Atmos. Chem. Phys., 9, 4261-4278, doi:10.5194/acp-9-4261-2009, 2009.
Krewski, D., Burnett, R. T., Goldberg, M. S., Hoover, K., Siemiatycki, J., Jerrett, M., Abrahamowicz, A., and White, W. H.: Reanalysis of the Harvard six cities study and the American Cancer Society study of particulate air pollution and mortality, A special report of the institute's particle epidemiology reanalysis project, 97 pp., Health Effects Inst., Cambridge, Mass., 2000.

Marley, N. A., Gaffney, J. S., Ramos-Villegas, R., and Cárdenas González, B.: Comparison of measurements of peroxyacyl nitrates and primary carbonaceous aerosol concentrations in Mexico City determined in 1997 and 2003, Atmos. Chem. Phys., 7, 2277-2285, doi:10.5194/acp-7-2277-2007, 2007.

Marley, N. A., Gaffney, J. S., Tackett, M., Sturchio, N. C., Heraty, L., Martinez, N., Hardy, K. D., Marchany-Rivera, A., Guilderson, T., MacMillan, A., and Steelman, K.: The impact of biogenic carbon sources on aerosol absorption in Mexico City, Atmos. Chem. Phys., 9, 1537-1549, doi:10.5194/acp-9-1537-2009, 2009a.

Marr, L. C., Dzepina, K., Jimenez, J. L., Reisen, F., Bethel, H. L., Arey, J., Gaffney, J. S., Marley, N. A., Molina, L. T., and Molina, M. J.: Sources and transformations of particle-bound polycyclic aromatic hydrocarbons in Mexico City, Atmos. Chem. Phys., 6, 1733-1745, doi:10.5194/acp-6-1733-2006, 2006.

Martonchik, J. V., Diner, D. J., Kahn, R. A., Ackerman, T. P., Verstraete, M. M., Pinty, B., and Gordon, H. R.: Techniques for the retrieval of aerosol properties over land and ocean using multiangle imaging, IEEE Trans. Geosci. Remote Sens., 36, 1212-1227, 1998.

Martonchik, J. V., Diner, D. J., Kahn, R. A., Gaitley, B., and Holben, B. N.: Comparison of MISR and AERONET aerosol optical depths over desert sites, Geophys. Res. Lett., 31, L16102, doi:10.1029/2004GL019807, 2004.

Martonchik, J. V., Kahn, R. A., and Diner, D. J.: Retrieval of aerosol properties over land using MISR observations, in: Satellite Aerosol Remote Sensing Over Land, edited by: Kokhanovsky, A. A. and de Leeuw, G., Berlin: Springer, 267-291, 2009.

Moffet, R. C., de Foy, B., Molina, L. T., Molina, M. J., and Prather, K. A.: Measurement of ambient aerosols in northern Mexico City by single particle mass spectrometry, Atmos. Chem. Phys., 8, 4499-4516, doi:10.5194/acp-8-4499-2008, 2008.

Molina, M. J. and Molina, L. T.: Critical Review: Megacities and atmospheric pollution, J. Air Waste Manage. Assoc., 54, 644680, 2004.

Molina, L. T., MaDronich, S., Gaffney, J. S., and Singh, H. B.: Overview of MILAGRO/INTEX-B Campaign, IGAC Newsletter, 38, 2-15, 2008.

Molina, L. T., Madronich, S., Gaffney, J. S., Apel, E., de Foy, B., Fast, J., Ferrare, R., Herndon, S., Jimenez, J. L., Lamb, B., Osornio-Vargas, A. R., Russell, P., Schauer, J. J., Stevens, P. S., Volkamer, R., and Zavala, M.: An overview of the MILAGRO 2006 Campaign: Mexico City emissions and their transport and transformation, Atmos. Chem. Phys., 10, 8697-8760, doi:10.5194/acp-10-8697-2010, 2010.

Paredes-Miranda, G., Arnott, W. P., Jimenez, J. L., Aiken, A. C., Gaffney, J. S., and Marley, N. A.: Primary and secondary contributions to aerosol light scattering and absorption in Mexico City during the MILAGRO 2006 campaign, Atmos. Chem. Phys., 9, 3721-3730, doi:10.5194/acp-9-3721-2009, 2009.

Pierce, J. R., Kahn, R. A., Davis, M. R., and Comstock J. M.: Detecting thin cirrus in Multiangle Imaging Spectroradiometer aerosol retrievals, J. Geophys. Res., 115, D08201, 
doi:10.1029/2009JD013019, 2010.

Querol, X., Pey, J., Minguillón, M. C., Pérez, N., Alastuey, A., Viana, M., Moreno, T., Bernabé, R. M., Blanco, S., Cárdenas, B., Vega, E., Sosa, G., Escalona, S., Ruiz, H., and Artíñano, B.: PM speciation and sources in Mexico during the MILAGRO-2006 Campaign, Atmos. Chem. Phys., 8, 111-128, doi:10.5194/acp8-111-2008, 2008.

Redemann, J., Zhang, Q., Livingston, J., Russell, P., Shinozuka, Y., Clarke, A., Johnson, R., and Levy, R.: Testing aerosol properties in MODIS Collection 4 and 5 using airborne sunphotometer observations in INTEX-B/MILAGRO, Atmos. Chem. Phys., 9, 8159-8172, doi:10.5194/acp-9-8159-2009, 2009.

Reid, J. S., Koppmann, R., Eck, T. F., and Eleuterio, D. P.: A review of biomass burning emissions part II: intensive physical properties of biomass burning particles, Atmos. Chem. Phys., 5, 799825, doi:10.5194/acp-5-799-2005, 2005.

Rogers, R. R., Hair, J. W., Hostetler, C. A., Ferrare, R. A., Obland, M. D., Cook, A. L., Harper, D. B., Burton, S. P., Shinozuka, Y., McNaughton, C. S., Clarke, A. D., Redemann, J., Russell, P. B., Livingston, J. M., and Kleinman, L. I.: NASA LaRC airborne high spectral resolution lidar aerosol measurements during MILAGRO: observations and validation, Atmos. Chem. Phys., 9, 4811-4826, doi:10.5194/acp-9-4811-2009, 2009.

Saldiva, P. H., Pope, C. A., Schwartz, J., Dockery, D. W., Lichtenfels, H. J., Salge, J. M., Barone, I., and Bohm, G. M.: Air pollution and mortality in elderly people: a time series study in Sao Paulo, Brazil, Arch. Environ. Health, 50, 159-163, 1995.

Schmid B., Redemann, J., Russell, P. B., Hobbs, P. V., Hlavka, D. L., McGill, M. J., Holben, B. N., Welton, E. J., Campbell, J. R., Torres, O., Kahn, R. A., Diner, D. J., Helmlinger, M. C., Chu, D. A., Gonzalez, C. R., and de Leeuw G.: Coordinated airborne, spaceborne, and ground-based measurements of massive, thick aerosol layers during the dry season in southern Africa, J. Geophys. Res., 108, 8496, doi:10.1029/2002JD002297, 2003.
Schwartz, J. and Marcus, A.: Mortality and air pollution in London: a time series analysis, Am. J. Epidemiol., 131, 185-94, 1990.

Shaw, W. J., Pekour, M. S., Coulter, R. L., Martin, T. J., and Walters, J. T.: The daytime mixing layer observed by radiosonde, profiler, and lidar during MILAGRO, Atmos. Chem. Phys. Discuss., 7, 15025-15065, doi:10.5194/acpd-7-15025-2007, 2007.

Singh, H. B., Brune, W. H., Crawford, J. H., Flocke, F., and Jacob, D. J.: Chemistry and transport of pollution over the Gulf of Mexico and the Pacific: spring 2006 INTEX-B campaign overview and first results, Atmos. Chem. Phys., 9, 2301-2318, doi:10.5194/acp-9-2301-2009, 2009.

Stone, E. A., Snyder, D. C., Sheesley, R. J., Sullivan, A. P., Weber, R. J., and Schauer, J. J.: Source apportionment of fine organic aerosol in Mexico City during the MILAGRO experiment 2006, Atmos. Chem. Phys., 8, 1249-1259, doi:10.5194/acp-81249-2008, 2008.

Voss, P. B., Zaveri, R. A., Flocke, F. M., Mao, H., Hartley, T. P., DeAmicis, P., Deonandan, I., Contreras-Jiménez, G., MartínezAntonio, O., Figueroa Estrada, M., Greenberg, D., Campos, T. L., Weinheimer, A. J., Knapp, D. J., Montzka, D. D., Crounse, J. D., Wennberg, P. O., Apel, E., Madronich, S., and de Foy, B.: Long-range pollution transport during the MILAGRO-2006 campaign: a case study of a major Mexico City outflow event using free-floating altitude-controlled balloons, Atmos. Chem. Phys., 10, 7137-7159, doi:10.5194/acp-10-7137-2010, 2010.

Wang, J., Christopher, S. A., Nair, U. S., Reid, J. S., Prins, E. M., Szykman, J., and Hand, J. L.: Mesoscale modeling of Central American smoke transport to the United States: 1. "Top-down" assessment of emission strength and diurnal variation impacts, J. Geophys. Res., 111, D05S17, doi:10.1029/2005JD006416, 2006.

Wang, J., Cubison, M. J., Aiken, A. C., Jimenez, J. L., and Collins, D. R.: The importance of aerosol mixing state and size-resolved composition on $\mathrm{CCN}$ concentration and the variation of the importance with atmospheric aging of aerosols, Atmos. Chem. Phys., 10, 7267-7283, doi:10.5194/acp-10-7267-2010, 2010. 